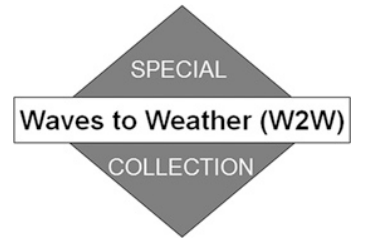

\title{
Aerosol Effects on Clouds and Precipitation over Central Europe in Different Weather Regimes
}

\author{
CHRISTIAN BARTHLOTT AND CORINNA HOOSE \\ Institute of Meteorology and Climate Research (IMK-TRO), Karlsruhe \\ Institute of Technology, Karlsruhe, Germany
}

(Manuscript received 11 April 2018, in final form 16 September 2018)

\begin{abstract}
The response of clouds to changes in the aerosol concentration is complex and may differ depending on the cloud type, the aerosol regime, and environmental conditions. In this study, a novel technique is used to systematically modify the environmental conditions in realistic convection-resolving simulations for cases with weak and strong large-scale forcing over central Europe with the Consortium for Small-Scale Modeling (COSMO) model. Besides control runs with quasi-operational settings, initial and boundary temperature profiles are modified with linear increasing temperature increments from 0 to $5 \mathrm{~K}$ between 3 and $12 \mathrm{~km}$ AGL to represent different amounts of convective available potential energy (CAPE) and relative humidity. The results show a systematic decrease of total precipitation with increasing cloud condensation nuclei $(\mathrm{CCN})$ concentrations for the cases with strong synoptic forcing caused by a suppressed warm-rain process, whereas no systematic aerosol effect is simulated for weak synoptic forcing. The effect of increasing CCN tends to be stronger in the simulations with increased temperatures and lower CAPE. While the large-scale domainaveraged responses to increased CCN are weak, the precipitation forming over mountainous terrain reveals a stronger sensitivity for most of the analyzed cases. Our findings also demonstrate that the role of the warmrain process is more important for strong than for weak synoptic forcing. The aerosol effect is largest for weakly forced conditions but more predictable for the strongly forced cases. However, more accurate environmental conditions are much more important than accurate aerosol assumptions, especially for weak largescale forcing.
\end{abstract}

\section{Introduction}

Aerosol-cloud interactions are one of the most uncertain processes in numerical weather prediction models. This is reflected by the increasing number of studies investigating aerosol-cloud interactions in the last few years, including a number of review papers that summarized past efforts and results (e.g., Tao et al. 2012; Altaratz et al. 2014; Fan et al. 2016). How aerosols affect clouds and precipitation strongly varies between cloud types that are controlled mainly by atmospheric dynamics and thermodynamics (Fan et al. 2016). In general, it is assumed that additional aerosols acting as cloud condensation nuclei $(\mathrm{CCN})$ result in more numerous and smaller cloud droplets. The increased reflectance of these brighter clouds is known as the albedo effect or the Twomey effect (Twomey 1977). The

Corresponding author: Christian Barthlott, christian.barthlott@ kit.edu reduced droplet size and the narrower droplet spectrum suppress the onset of precipitation in warm clouds as result of the less efficient collision-coalescence process. This results in a longer cloud lifetime (lifetime effect; Albrecht 1989). Many recent studies documented that the response of clouds to changes in the aerosol concentration is complex and may differ depending on the cloud type or aerosol regime and environmental conditions (e.g., Seifert and Beheng 2006b; Khain et al. 2008; van den Heever et al. 2011).

For deep convective clouds in polluted air, it is assumed that the smaller droplets do not precipitate before reaching the supercooled levels (Rosenfeld et al. 2008). The larger water load at the freezing level results in an additional release of latent heat, leading to an invigoration of convection with additional rainfall. Even in absence of such a thermodynamic invigoration, Fan et al. (2013) found that aerosol's microphysical effects can lead to a dramatic increase in cloud cover, cloud-top height, and cloud thickness at the mature and dissipation stages 
by inducing larger amounts of smaller but longer-lasting ice particles in the stratiform anvils under polluted conditions. As documented in the review by Tao et al. (2012), the effect of aerosols on cloud formation and subsequent precipitation varies in sign and magnitude for different situations. For example, the simulations of a hailstorm by Noppel et al. (2010) showed both an increase and a decrease in total precipitation depending on the case setup and environmental conditions. Even if enhanced $\mathrm{CCN}$ concentrations lead to an invigoration of convection, the condensate loss in polluted clouds can be larger than in clean-air clouds if the precipitating droplets fall through dry layers before reaching the ground (Khain and Pokrovsky 2004; Khain et al. 2008). Moreover, the reduction in collision and coalescence was also found to offset any increase in condensate amounts from updraft invigoration by latent heating (Storer and van den Heever 2013). According to Altaratz et al. (2014), the validity of the invigoration hypothesis is still an open question. Among other processes, they assume that there is a turning point between cloud suppression and cloud invigoration, depending on the cloud size and the environmental conditions (temperature, relative humidity, and wind shear). Using idealized simulations, Grant and van den Heever (2015) showed that aerosol effects on deep convective clouds are also modulated by the altitude of dry layers and that the aerosol impacts vary inversely with the storm organization. A variable response to the increase in aerosol loading was also found by van den Heever et al. (2011). In their numerical study, they found that the aerosol effects varied for trade cumulus, cumulus congestus, and cumulonimbus clouds. The smaller warm clouds were suppressed, whereas the stronger updrafts of the bigger clouds lead to a larger liquid water path and increased precipitation. Precipitation from shallow convective clouds generally tends to be suppressed by increased CCN concentrations as a result of a less efficient warm-rain process via collision-coalescence (Tao et al. 2012). Fan et al. (2017) conducted a study on orographic clouds in warm and cold mixed-phase clouds and found that adding $\mathrm{CCN}$ suppresses precipitation especially in warm mixed-phase clouds with low ice nucleating particles. For high CCN concentrations, however, they found increased precipitation resulting from an invigoration of mixed-phase clouds.

As was pointed out by Fan et al. (2016), the large variability of cloud physics parameterizations results in a large spread of modeling results. Moreover, uncertainty from the choice of the microphysics scheme seems to significantly exceed aerosol effects (White et al. 2017). According to Stevens and Feingold (2009), it is difficult to establish climatically meaningful relationships among the aerosol, clouds, and precipitation because of microphysical and macrophysical (cloud dynamical) effects that may also buffer the response of the system to aerosol perturbations.
Seifert et al. (2012) found that in convection-permitting simulations for three summer seasons of a domain covering Germany, the average effect of varying aerosol concentrations on precipitation was negligible because of buffering effects. Such buffering impacts were also found, for example, by van den Heever et al. (2011). In simulations for the 2014 Pentecost storms over Germany, Barthlott et al. (2017) found that different CCN assumptions reveal a systematic relationship for condensate amounts of cloud water, rain, and ice with increasing $\mathrm{CCN}$. The evaporation of raindrops at lower levels, however, leads to a nonsystematic response of accumulated precipitation to $\mathrm{CCN}$.

The numerical simulations in the available literature on aerosol-cloud interactions can be broadly classified into (i) idealized (e.g., Altaratz et al. 2008; Storer et al. 2010; van den Heever et al. 2011; Adams-Selin et al. 2013; Storer and van den Heever 2013; Kalina et al. 2014; Saleeby et al. 2015) and (ii) realistic simulations (e.g., Noppel et al. 2010; Seifert et al. 2012; Fan et al. 2017; Barthlott et al. 2017). Idealized simulations have the advantage that the environmental conditions can be changed easily, as one single profile is used to initialize the model at all grid points. Often the number of grid points is lower than for real-case simulations and numerous sensitivity runs can be performed at moderate computational costs. The drawback, however, is the fact that an artificial trigger process (e.g., heat bubble, cold pool, mountain) is needed to initiate convection. As was pointed out by Noppel et al. (2010), such idealized simulations often show different sensitivities of aerosolcloud interactions than the simulation of real cases.

In this paper, we expand this line of investigation by performing convection-resolving simulations of real weather events, but applying a novel technique of systematically modifying temperature profiles of the initial and boundary data. The modified temperature profiles then lead to differences in the stability and relative humidity, both of which are highly relevant to cloud formation and precipitation. The advantage of this method is that the dominating weather regime and the environmental conditions in the planetary boundary layer and at cloud base are not changed. To cover different weather regimes, this technique is applied to days with weak synoptic forcing (airmass convection) and strong synoptic forcing (passage of frontal zones). In each of these realizations, we additionally conduct simulations with different $\mathrm{CCN}$ concentrations covering maritime (m), intermediate (i), continental (c), and continental-polluted (cp) conditions. This study is unique because it examines the sensitivity of aerosol-cloud interactions for real weather events over a range of thermodynamic conditions. Such process-level studies are needed to improve our understanding of aerosol-cloud interactions in different meteorological environments. 


\section{Method}

\section{a. Model description}

All numerical simulations were produced with version 5.3 of the nonhydrostatic limited-area atmospheric prediction model provided by the Consortium for Small-Scale Modeling (COSMO) (Schättler et al. 2016). The COSMO model is used by the German Weather Service for operational weather forecasting; its operational domain covers Germany, parts of the neighboring countries, and most of the Alps (Fig. 1). In contrast to the operational setup (Baldauf et al. 2011), we use a sophisticated doublemoment microphysics scheme based on Seifert and Beheng (2006a) that predicts both the mass mixing ratio and the number concentrations of the different hydrometeors. This scheme has been designed specially to represent aerosol effects on the microphysics of mixed-phase clouds and also includes a separate hail class considering wet growth processes and a spectral partitioning of freezing raindrops. Despite the more expensive computations, the benefits of using a double-moment scheme, which were documented for both idealized (e.g., Adams-Selin et al. 2013; Dawson II et al. 2010) and realistic cases (e.g., Molthan and Colle 2012), strongly suggest using a doublemoment scheme when a realistic reproduction of the atmosphere is desired (Igel et al. 2015). In the Seifert and Beheng (2006a) scheme, the activation of $\mathrm{CCN}$ from aerosol particles is computed using precalculated activation ratios stored in lookup tables by Segal and Khain (2006). These activation ratios depend on the properties of the aerosol and the vertical velocity at cloud base. The lookup tables were derived assuming all condensation nuclei $(\mathrm{CN})$ being soluble and exhibiting a bimodal size distribution. In contrast to the initial assumptions of the Segal and Khain (2006) scheme, CN are often not completely soluble. An additional simple correction factor $\varepsilon$ was introduced to adjust the number of nucleated droplets to particles with different soluble fractions (Seifert et al. 2012; Noppel et al. 2010). To investigate aerosolcloud interactions, we performed numerical simulations with maritime, intermediate, continental, and continental polluted conditions for which the number density of condensation nuclei $N_{\mathrm{CN}}$, the mean radius of the larger aerosol mode $R_{2}$, and the logarithm of the mode's standard deviation $[\log (\sigma)]$ are prescribed (Table 1$)$. Typical conditions of central Europe are represented by the continental aerosol assumption (Hande et al. 2016). Similar to other double-moment schemes (e.g., Cohard and Pinty 2000; Milbrandt and Yau 2005; Morrison et al. 2009; Dipankar et al. 2015), the COSMO model uses a saturation adjustment instead of saturation prediction. As was stated by Seifert and Beheng (2006a), all clouds, except extremely

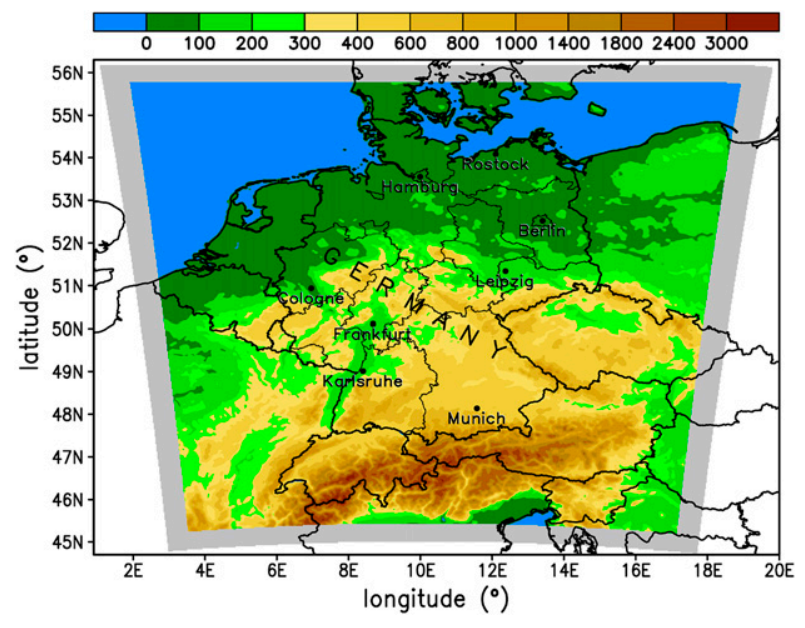

FIG. 1. COSMO simulation domain and orography (m MSL). The gray-shaded area indicates the relaxation zone (width of $50 \mathrm{~km}$ ) not included in our analyses.

maritime ones, relax rapidly to the thermodynamic equilibrium between water vapor and water drops so that applying the standard saturation adjustment technique to treat condensational growth seems to be appropriate in almost all cases. However, recent findings by Lebo et al. (2012) and Grabowski and Morrison (2017) suggest that the use of a saturation adjustment has implications on cloud development and surface rain amounts through enhanced latent heating at lower levels, which limits the potential for a $\mathrm{CCN}$ increase to increase buoyancy at midto upper levels. Grabowski and Morrison (2017) also state that the impact on surface precipitation is minor and that subsequent studies using models with different representations of cloud microphysics and simulating clouds in different environments are needed. The COSMO model uses a rotated latitude-longitude grid with terrainfollowing hybrid height coordinates. Deep convection is resolved explicitly, while shallow convection is parameterized using a modified Tiedtke mass-flux scheme with moisture-convergence closure (Tiedtke 1989). Shallow convection is nonprecipitating and limited to a cloud depth of $250 \mathrm{hPa}$. Only temperature and moisture are directly affected by shallow convection (for details see Baldauf et al. 2011; Theunert and Seifert 2006). All simulations were performed on the operational COSMO domain in Germany (COSMO-DE; Fig. 1). An overview of the model configuration is given in Table 2.

\section{b. Modification of initial and boundary files}

For each of the days analyzed in this study, we performed a reference (REF) run with quasi-operational settings. To assess the sensitivity of aerosol-cloud interactions on thermodynamic properties, we modified the initial and boundary temperature fields with increasing 
TABLE 1. Parameters used for calculating cloud droplet nucleation.

\begin{tabular}{lcccc}
\hline \hline CCN concentration & $N_{\mathrm{CN}}\left(\mathrm{cm}^{-3}\right)$ & $\log (\sigma)$ & $R_{2}$ & $\varepsilon$ \\
\hline Maritime & 100 & 0.4 & 0.03 & 0.9 \\
Intermediate & 500 & 0.4 & 0.03 & 0.8 \\
Continental & 1700 & 0.2 & 0.03 & 0.7 \\
Continental polluted & 3200 & 0.2 & 0.03 & 0.7 \\
\hline
\end{tabular}

and decreasing temperature increments, referred to as sensitivity experiments INC and RED, respectively. As can be seen in Fig. 2, the temperature increments are linearly increasing (decreasing) from 0 to $\pm 5 \mathrm{~K}$ between 3 and $12 \mathrm{~km}$ AGL. Above a height of $12 \mathrm{~km}$, the increment is constant up to the model top. Different values for the maximum temperature increment $(2,3$, and $5 \mathrm{~K})$ and height ranges (3-12 and 5-12 km AGL) were tested for various cases to determine a meaningful configuration. It turned out that the maximum temperature increment of $5 \mathrm{~K}$ in the height range between 3 and $12 \mathrm{~km}$ AGL produced distinct changes in the simulation results without changing the dominant weather regime. Moreover, the environmental conditions in the planetary boundary layer for convection initiation and at the cloud base remain unchanged. The obvious effect of this modification is on the stability of the atmosphere by directly increasing or decreasing the lapse rate. Given that the cloud base remains more or less unaffected, the convective available energy (CAPE) will be larger for the runs with decreased temperature values. This is due to the higher level of equilibrium as rising air parcels transect the temperature profile at a higher height in the atmosphere. Another direct effect is the modification of the relative humidity that increases (decreases) for decreasing (increasing) temperature values (Fig. 2b). While the relative humidity depends on temperature, the specific humidity is unaffected by these modifications. Thus, the total amount of moisture (e.g., reflected by the precipitable water) remains unaltered as well. This guarantees a meaningful intercomparison between individual sensitivity runs, as the available amount of moisture for precipitation is the same for each day. To exclude processes occurring at the domain boundaries of the model, we omit the relaxation zone (marked by the gray shaded area in Fig. 1) with a width of $50 \mathrm{~km}$ from our analyses. The set of sensitivity runs used here comprises six cases with unchanged initial and boundary conditions and with increased and decreased temperature profiles. For each of these sets, we conduct simulations with four different CCN assumptions, leading to a total set of 72 simulations. To ensure that our temperature modifications of $\pm 5 \mathrm{~K}$ are within the range of natural variability, radiosonde data from a station centered over Germany were analyzed over an 11-yr period (2007-17). We
TABLE 2. Model configurations for the COSMO simulations.

\begin{tabular}{|c|c|}
\hline Model aspect & Setting \\
\hline Grid & $\begin{array}{l}\text { Arakawa } \mathrm{C}, \Delta x=2.8 \mathrm{~km}, 421 \times \\
\quad 461 \text { grid points }\end{array}$ \\
\hline Vertical levels & $\begin{array}{l}50 \text { (terrain-following, height- } \\
\text { based hybrid vertical } \\
\text { coordinate) }\end{array}$ \\
\hline Lowest model level & $\begin{array}{l}10 \mathrm{~m} \text { AGL (12 levels below } 1 \mathrm{~km} \\
\text { AGL) }\end{array}$ \\
\hline Model top & $22 \mathrm{~km}$ \\
\hline $\begin{array}{l}\text { Initial and } \\
\text { boundary data }\end{array}$ & $\begin{array}{l}\text { 7-km COSMO-EU analyses, 1-h } \\
\text { update }\end{array}$ \\
\hline Time step & $25 \mathrm{~s}$ \\
\hline Initialization time & $0000 \mathrm{UTC}$ \\
\hline Integration time & $24 \mathrm{~h}$ \\
\hline Time integration & $\begin{array}{l}\text { Two-time-level Runge-Kutta } \\
\text { method (Wicker and } \\
\text { Skamarock 2002) }\end{array}$ \\
\hline Microphysics & $\begin{array}{l}\text { Double-moment bulk } \\
\text { microphysics (Seifert and } \\
\text { Beheng 2006a) }\end{array}$ \\
\hline $\begin{array}{l}\text { Convection } \\
\text { parameterization }\end{array}$ & $\begin{array}{l}\text { Deep convection resolved } \\
\text { explicitly, shallow convection } \\
\text { parameterized (Tiedtke 1989) }\end{array}$ \\
\hline Land surface model & TERRA (Heise et al. 2006) \\
\hline $\begin{array}{l}\text { Turbulence } \\
\text { parameterization }\end{array}$ & $\begin{array}{l}\text { 1D based on prognostic equation } \\
\text { for the turbulent kinetic energy } \\
\text { (Mellor and Yamada 1974) }\end{array}$ \\
\hline Radiation scheme & $\begin{array}{l}\text { Ritter and Geleyn (1992), called } \\
\text { every } 15 \text { min }\end{array}$ \\
\hline Data assimilation & None \\
\hline
\end{tabular}

found that for all cases described in the next section, reduced and increased 200-hPa temperatures (approximately $12 \mathrm{~km} \mathrm{AGL)}$ are within the range of observed variability.

\section{Case studies analyzed}

\section{a. Synoptic conditions and observed precipitation}

We classify the cases according to the synoptic conditions into (i) weak large-scale forcing with prevailing convective clouds and (ii) strong large-scale forcing with more stratiform clouds. For each of these classes, we conducted simulations for three individual days (Table 3). One of these days (i.e., 26 April 2013) covers an intensive observation period of the High Definition Clouds and Precipitation for Advancing Climate Prediction $\left[\mathrm{HD}(\mathrm{CP})^{2}\right]$ Observational Prototype Experiment (HOPE) field campaign conducted in midwestern Germany in spring 2013 (Macke et al. 2017). This day was simulated also with several model resolutions in the gray zone by Barthlott and Hoose (2015) and with largeeddy simulations (Heinze et al. 2017). The precipitation response to terrain forcing on cases 30 June 2009, 23 July 


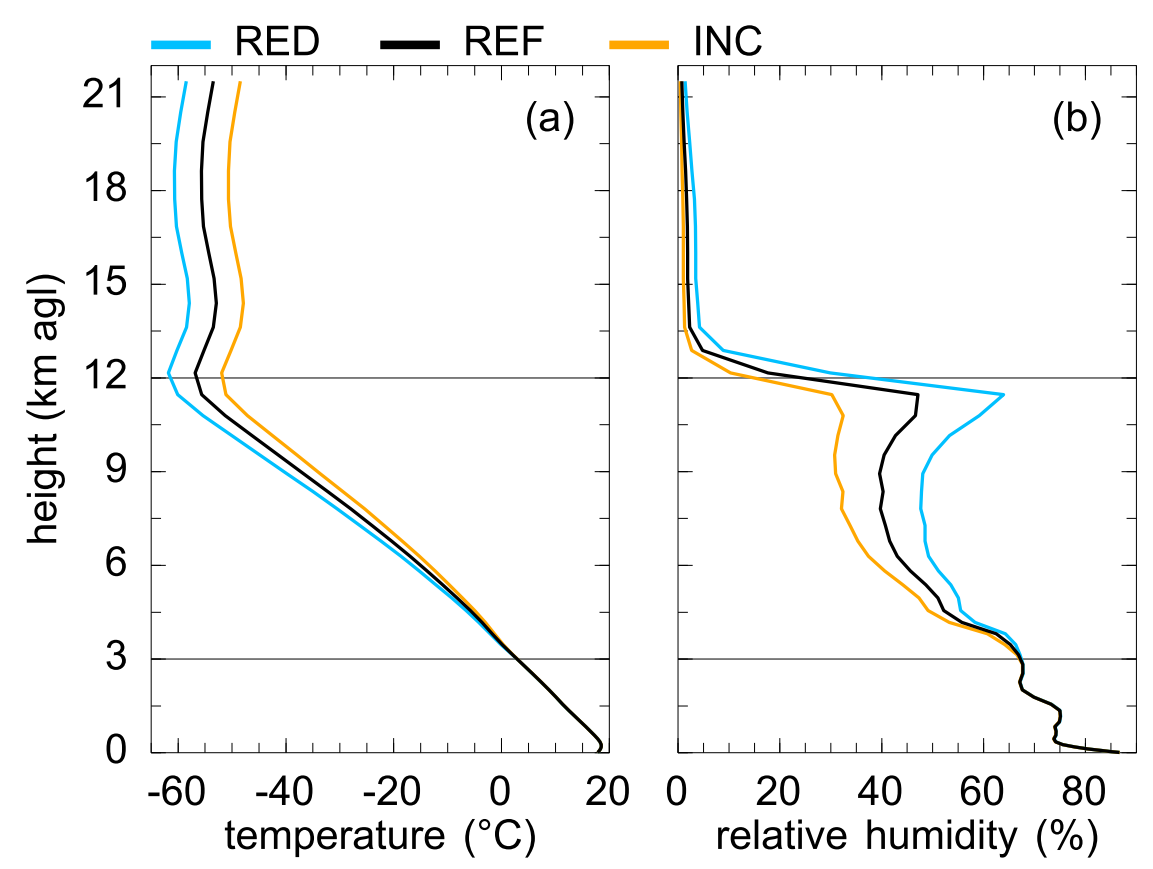

FIG. 2. Domain-averaged profiles of (a) temperature and (b) relative humidity for the original and modified atmospheric fields.

2013, and 11 September 2013 was also investigated by high-resolution simulations (500-m horizontal grid spacing) by Schneider et al. (2018). For a more quantitative evaluation of the large-scale forcing, we calculated the convective adjustment time scale $\tau$ as

$$
\tau=0.5\left(\frac{\rho_{0} c_{p} T_{0}}{L_{v} g}\right) \frac{\mathrm{CAPE}}{P}
$$

with reference values for density $\rho_{0}=1.292 \mathrm{~kg} \mathrm{~m}^{-3}$ and temperature $T_{0}=273.15 \mathrm{~K}$, specific heat of air at constant pressure $c_{p}$, latent heat of vaporization $L_{v}$, the acceleration caused by gravity $g$, and the precipitation rate $P$ following Keil et al. (2014). If $\tau$ is smaller (larger) than a threshold lying between 3 and $12 \mathrm{~h}$, then the large-scale forcing is strong (weak). The daily averages of this time scale confirm our classification done by visual inspection of synoptic weather charts (Table 3).

As can be seen in Figs. 3a-c, the weather regime in central Europe is dominated by a ridge on all days with weak synoptic forcing. The axis of the ridge lies over France on both cases from 2009 (30 June and 2 July) and farther to the east on 23 July 2013. Low pressure is present over the eastern Atlantic, and midtropospheric winds are weak over Germany with northerly (Fig. 3a), northeasterly (Fig. 3b), and northwesterly (Fig. 3c) winds. The surface pressure on all these days lies between 1016 and $1020 \mathrm{hPa}$ with weak gradients.
Figure 4 shows 24-h precipitation amounts from the precipitation analysis algorithm Radar Online Adjustment (RADOLAN). It combines weather radar data with hourly surface precipitation observations of about 1300 automated rain gauges to get quality-controlled, high-resolution $(1 \mathrm{~km})$ quantitative precipitation estimations. For the cases with weak large-scale forcing (Figs. 3a-c), the cellular structure of precipitation indicates the missing frontal systems on these days. On 30 June 2009, precipitation occurs in western and eastern Germany, whereas more uniformly distributed convective showers were observed on 2 July 2009. On the latter day, only northern Germany shows no or only small amounts of rain. On 23 July 2013, convective precipitation is restricted to southwestern Germany.

The cases with strong synoptic forcing are characterized by a stronger baroclinicity of the flow (bottom rwos

TABLE 3. Analyzed days and classification of synoptic forcing with the convective adjustment time scale $\tau$.

\begin{tabular}{llrcc}
\hline $\begin{array}{c}\text { Large-scale } \\
\text { forcing }\end{array}$ & \multicolumn{1}{c}{ Date } & $\tau(\mathrm{h})$ & $\overline{\mathrm{CAPE}}\left(\mathrm{J} \mathrm{kg}^{-1}\right)$ & $\bar{P}\left(\mathrm{~mm} \mathrm{~h}^{-1}\right)$ \\
\hline Weak & 30 Jun 2009 & 20.2 & 308 & 0.195 \\
Weak & 2 Jul 2009 & 20.6 & 344 & 0.198 \\
Weak & 23 Jul 2013 & 59.9 & 174 & 0.140 \\
Strong & 26 Apr 2013 & 0.2 & 6 & 0.432 \\
Strong & 11 Sep 2013 & 0.5 & 24 & 0.393 \\
Strong & 18 Apr 2014 & 0.3 & 8 & 0.198 \\
\hline
\end{tabular}



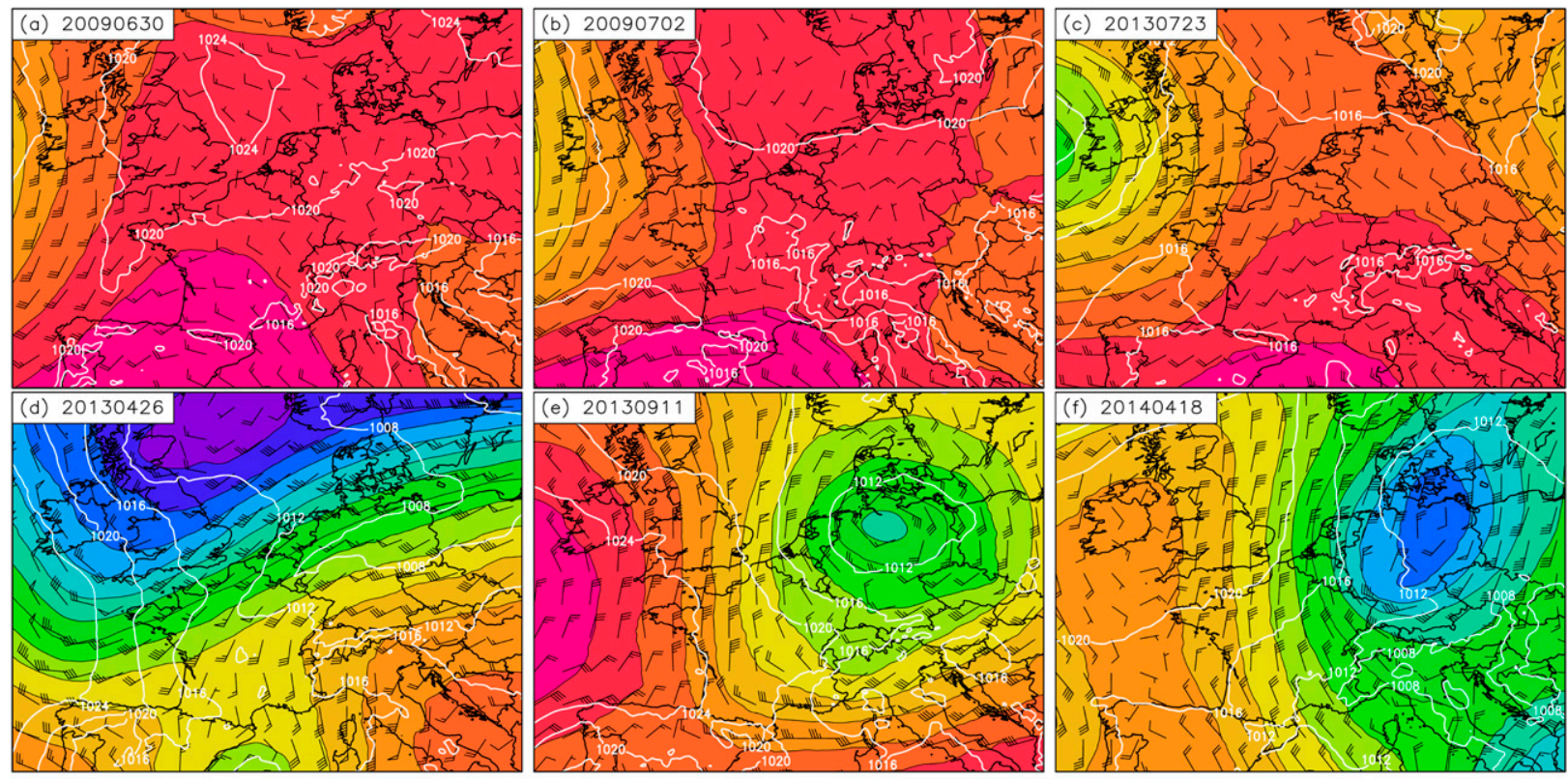

$\begin{array}{lllllllllllllll}528 & 532 & 536 & 540 & 544 & 548 & 552 & 556 & 560 & 564 & 568 & 572 & 576 & 580 & 584\end{array}$

FIG. 3. COSMO Europe (COSMO-EU) 7-km-grid-length analyses at 1200 UTC for the cases with (a)-(c) weak and (d)-(f) strong large-scale forcing showing 500-hPa geopotential height (gpdm; shading), sea level pressure (hPa; white contours), and 500-hPa wind barbs.

of Figs. 3 and 4). A trough is located over the British Isles on 26 April 2013. Germany is situated downstream of this trough in a strong southwesterly flow. The passage of a cold front leads to a stratiform rain distribution over almost all of Germany with signals of embedded convection (Fig. 4d). On the remaining 2 days (11 September 2013 and 18 April 2014), a low pressure system is situated over northern Germany. The midtropospheric flow is cyclonic with stronger winds on the last case as a result of a deeper low and stronger pressure gradients. Large parts of Germany are covered by precipitation on both days. On 11 September 2013, there are indications of orographic precipitation enhancement (e.g., Kirshbaum et al. 2018) over the Black Forest mountains in southwestern Germany (south of Karlsruhe).

\section{b. Evaluation of REF runs}

This study focuses on the sensitivity of simulated precipitation to changes in the aerosol content and thermodynamical conditions of the atmosphere. Nevertheless, we have evaluated the respective reference runs at least in a qualitative way to ensure that the COSMO model simulates the main weather characteristics on the analyzed days reasonably well. The simulated 24 -h precipitation amount of the reference runs with continental CCN displayed in Fig. 5 show good agreement with observations (Fig. 4) for all days. Not only the convective or stratiform character of precipitation, but also the location and amounts are mostly simulated well by the model. Differences exist mainly for weak large-scale forcing, for example, (i) too much rain in central Germany on 30 June 2009 and (ii) too little rain near Cologne, Germany, on 2 July 2009 and in southern Germany on 23 July 2013. The model performance is generally better on days with strong large-scale forcing. This reflects the fact that the COSMO model (and many other operational models, too) still has difficulty correctly describing convection initiation at the right time and place in airmass convection situations (Baldauf et al. 2011). Based on the fact that the model succeeds reasonably well in reproducing the observed weather characteristics, we conclude that the reference runs serve as a good basis for our sensitivity studies.

\section{Results}

\section{a. Precipitation totals and timing}

As expected, the 24-h precipitation amounts with reduced temperatures are always higher than the respective reference runs irrespective of the existence of large-scale forcing (Fig. 6). This can be explained by the steeper lapse rates and increased instability as well as the higher relative humidity. On the other hand, precipitation is reduced in all INC runs as a result of lower relative humidity and decreased CAPE. Beyond this 


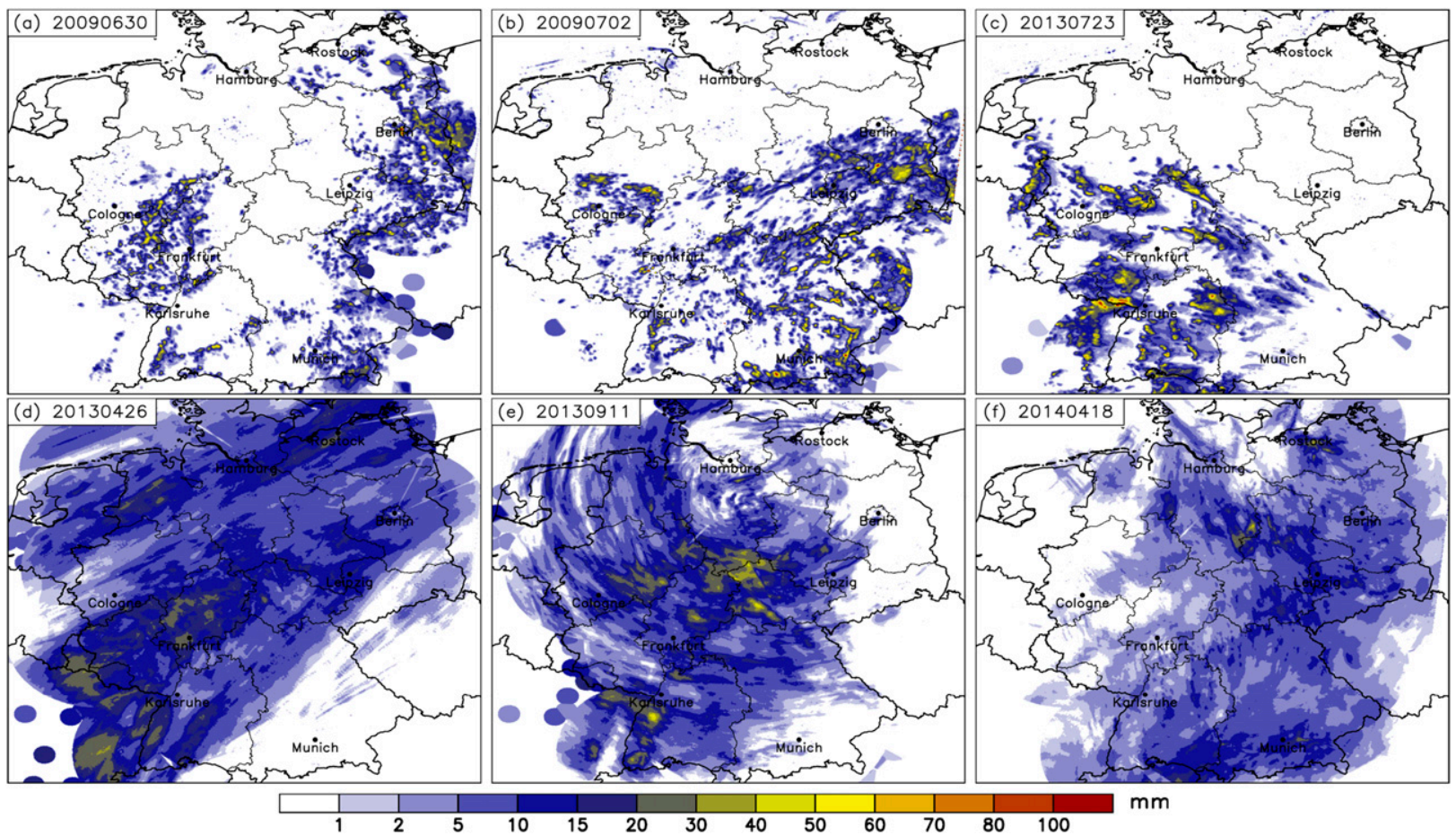

FIG. 4. Radar-derived 24-h precipitation amount from RADOLAN for the cases with (a)-(c) weak and (d)-(f) strong large-scale forcing.

obvious feature, the analysis of the sensitivity of the individual runs to the aerosol load reveals that the model simulates a systematic precipitation decrease with increased $\mathrm{CCN}$ content for the cases with strong synoptic forcing. However, the percentage deviations from the reference run (i.e., the run with continental $\mathrm{CCN}$ assumption) for all grid points is rather low (range is $-1.5 \%$ to $3.4 \%$ ). In contrast to this systematic dependence, the cases with weak large-scale forcing show a different behavior. For one day (23 July 2013), there is a systematic precipitation increase with increasing CCN and a stronger response to the aerosol load $(-7.2 \%$ to $+3.8 \%$ ), while there is no systematic response on 30 June and 2 July 2009 . When analyzing only mountainous terrain (grid points with terrain elevation higher than $500 \mathrm{~m} \mathrm{MSL}$ ), there is the same systematic dependence of accumulated precipitation to the prescribed $\mathrm{CCN}$ content for the cases with strong synoptic forcing. For the days with airmass convection, again, there is no systematic relationship. Interestingly, the percentage deviations for mountainous terrain (ranging between $-8.1 \%$ and $+7.4 \%$ ) are higher than in the entire model domain $(-7.2 \%$ to $+3.8 \%)$. In fact, for all strongly forced cases and one weakly forced case, the aerosol effect on precipitation is larger over mountainous terrain (14 out of 18 sets of simulations). Only the runs with reduced and reference temperatures on 2 July 2009 and 23 July 2013 show a smaller response over mountainous terrain.
In these cases, however, a large fraction of the precipitation falls over flat terrain, which might explain the different behavior. This indicates that even when the effects of aerosols on precipitation averaged over space and time are relatively small, locally stronger variations can occur. These deviations are not negligible and indicate an agreement with findings by Barthlott et al. (2017) that $\mathrm{CCN}$ assumptions are indeed important for quantitative precipitation forecasting. The larger aerosol effect for mountainous terrain can be explained by the fact that precipitation in shallow convective clouds generally tends to be suppressed by increased $\mathrm{CCN}$ concentrations as a result of the less efficient warm-rain process via collisioncoalescence. In low CCN conditions, the fast rain formation is coupled to the dynamical forcing of the orography that leads to larger precipitation amounts (see also Seifert et al. 2012). When the CCN content is high, the slower rain formation reduces the impact of orographic obstacles. When averaged over space, the effect becomes smaller. To confirm this hypothesis, we calculated the change of autoconversion (AC) rates over mountainous areas (terrain height greater than $500 \mathrm{~m} \mathrm{AGL)} \mathrm{and} \mathrm{flat} \mathrm{terrain}$ separately. Over mountainous terrain, the percentage reduction of autoconversion rates with increasing CCN concentrations is always higher than over flat terrain. Moreover, the difference between the percentage reduction over flat and mountainous terrain is higher for cases with strong synoptic forcing $(14 \%)$, which produce 


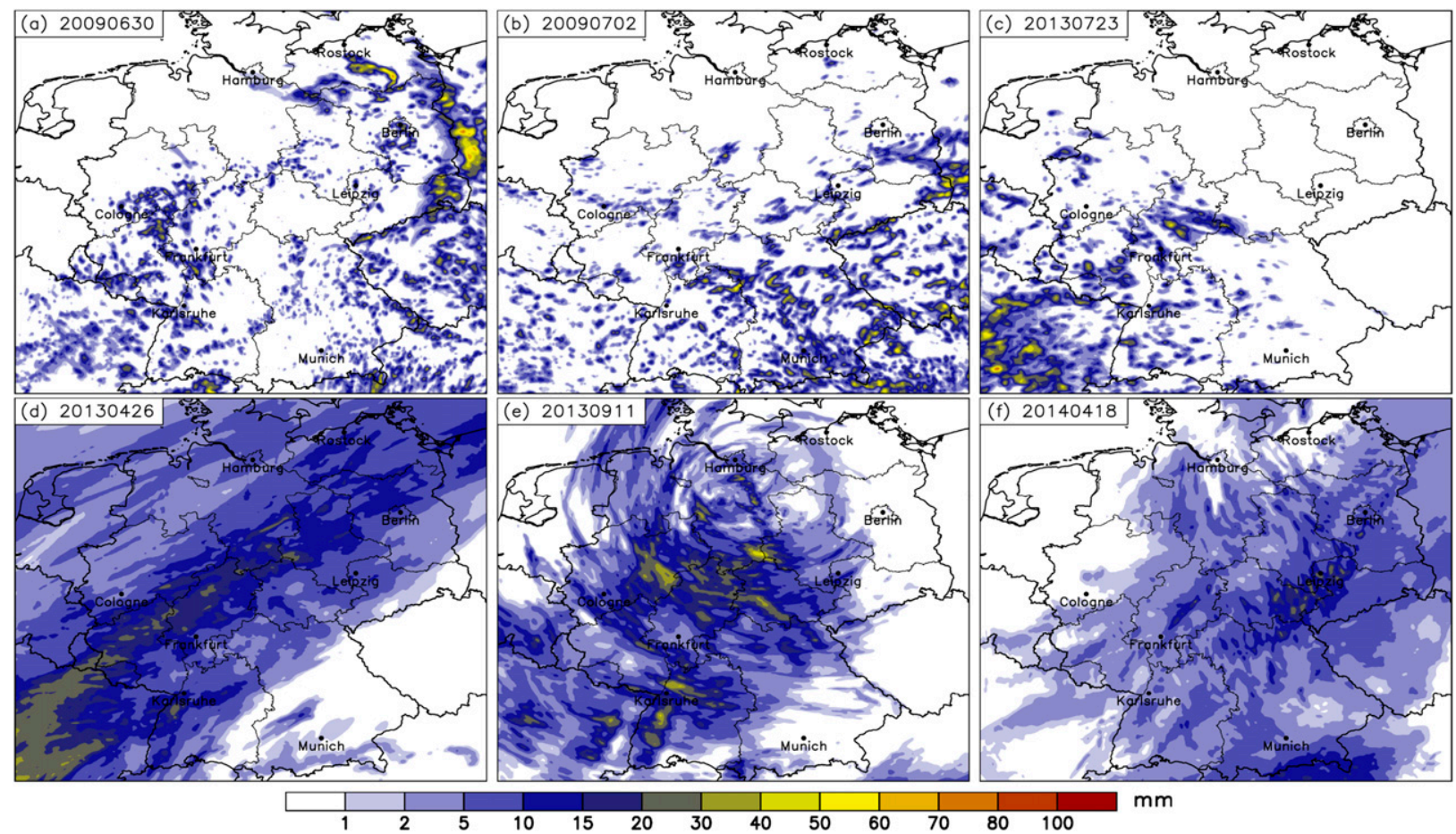

FIG. 5. 24-h precipitation amount of the REF runs assuming continental aerosol conditions.

more shallow clouds and orographic precipitation, than for weak synoptic forcing (4\%).

The approach of modifying the temperature profiles in the free troposphere enables us to elucidate the precipitation response to the aerosol amount for the same weather regime, but with moderate changes in stability and CAPE. By comparing the total range of percentage precipitation deviations (i.e., the difference between the largest and smallest percentage deviations from the respective reference run) of each set in Fig. 6, we find a systematic increase with increased upper-level temperatures in four out of six cases. These comprise all three strong forcing cases and one with weak forcing case (30 June 2009). That means that the aerosol effect decreases for increased instability (colder temperatures), at least for cases with strong synoptic forcing.

In agreement with the larger (lower) rain amounts of the RED (INC) run with respect to the reference run, the model always simulates higher rain intensities for reduced temperatures and smaller ones for increased temperatures (Fig. 7). Whereas the evolution on days with strong synoptic forcing is very similar, the time of maximum rain intensities on days with weak forcing occurs $1-1.5 \mathrm{~h}$ later for colder temperatures as a result of larger amounts of CAPE. The sensitivity of rain intensities to the aerosol amount is very weak on days with strong synoptic forcing. Only during the respective periods with the highest rain intensities does the model simulate slightly higher rain intensities the lower the aerosol load is. The systematic reduction with increasing $\mathrm{CCN}$ is in agreement with the reduction of accumulated precipitation for the days with strong synoptic forcing (see Fig. 6). On the other hand, the days with weak synoptic forcing reveal differences in the mean rain intensity for longer time periods throughout the day. The differences between the aerosol sensitivity runs become larger for stronger rain intensities.

To investigate differences in the spatial distribution of accumulated precipitation, we calculated probability distributions of precipitation differences for all grid points in the evaluation domain. As the distributions for the individual weather regime (i.e., weak or strong forcing) are similar, we present only one day of each class in Fig. 8. It can be seen that the case with weak large-scale forcing shows much higher maximum differences $(-91$ and $+81 \mathrm{~mm}$ ) and a wider distribution than that of the case with strong forcing $(-31$ and $+37 \mathrm{~mm})$. The simulations with reduced (increased) temperature profiles possess the largest (smallest) precipitation deviations with the reference runs in between. This can be explained by the fact that when more precipitation is simulated because of higher CAPE, the possible impacts of aerosols on cloud evolution and dynamics can be larger as well. It is also remarkable that the small deviations $( \pm 4 \mathrm{~mm})$ have similar probabilities of occurrence for all temperature and CCN assumptions, whereas only the larger deviations show an influence of temperature profile and 


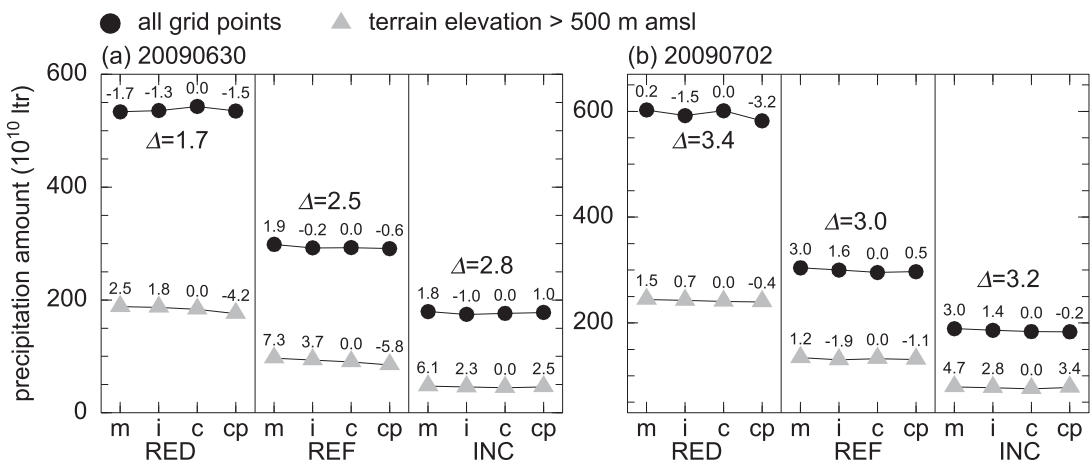

(c) 20130723

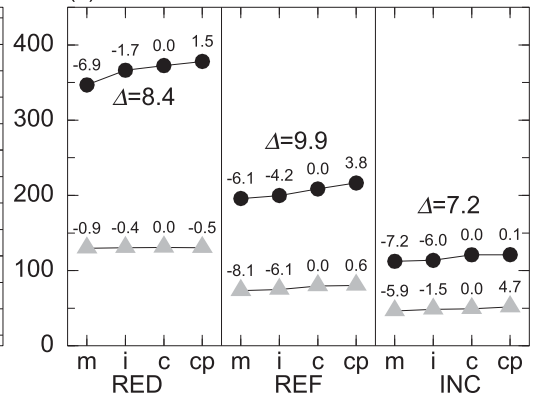

(e) 20130911

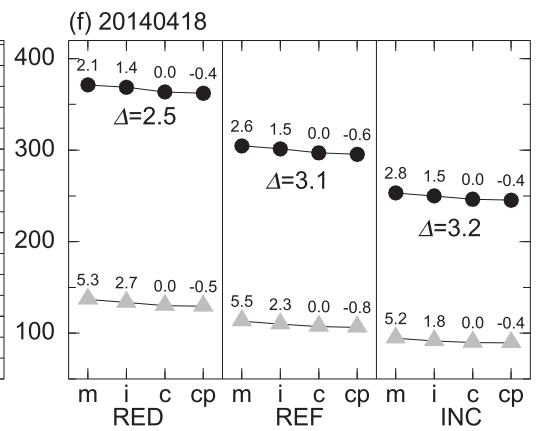

FIG. 6. 24-h precipitation amount for the cases with (a)-(c) weak and (d)-(f) strong large-scale forcing. Numbers give percentage deviations from the respective run assuming continental CCN conditions typical for the area of investigation: maritime $\left(N_{\mathrm{CN}}=100 \mathrm{~cm}{ }^{-3}\right)$, intermediate $\left(N_{\mathrm{CN}}=500 \mathrm{~cm}^{-3}\right)$, continental $\left(N_{\mathrm{CN}}=1700 \mathrm{~cm}^{-3}\right)$, and continental polluted $\left(N_{\mathrm{CN}}=3200 \mathrm{~cm}^{-3}\right) \mathrm{CCN}$ assumptions. The range of percentage precipitation deviation $\Delta$ is the difference between the largest and smallest percentage deviations from the respective reference run. RED, REF, and INC indicate runs with reduced, reference, and increased temperature profiles.

aerosol content. A sensitivity to the prescribed $\mathrm{CCN}$ concentration is hardly visible under strong synoptic forcing. For weak forcing, however, all three temperature regimes show the highest deviations for the maritime cases. These findings demonstrate that even when the accumulated precipitation over a large domain shows only small differences with respect to different aerosol assumptions, there can be large spatial variations at least for weak large-scale forcing. Especially for flood forecasting or the occurrence of wind gusts (Mohr et al. 2017), the precise simulation of precipitation is of high importance. As pointed out earlier for mountainous terrain, these findings support the conclusion that $\mathrm{CCN}$ assumptions are important for quantitative precipitation forecasting. Although the precipitation response to different $\mathrm{CCN}$ assumptions is not systematic, the largest precipitation deviations occur for weak synoptic forcing. However, the role of the environmental conditions analyzed in this study (temperature stratification and CAPE) is larger than the aerosol effect. For weakly forced cases, these conditions are far more important than for cases with strong synoptic forcing. We therefore conclude that convective weather regimes are more susceptible to changes in the ambient temperature profile than weather regimes associated with frontal systems.

\section{b. Cloud statistics}

Figure 9 shows that for all days analyzed, the lower the temperature profiles, the larger the cloud fraction is in the middle and upper troposphere. The sensitivity of the cloud fraction to temperature modifications is largest for weak large-scale forcing as a result of the more intense convection for the higher CAPE regimes and the formation of anvil clouds below the tropopause. Also, the sensitivity to the prescribed $\mathrm{CCN}$ content is larger for the reduced temperatures (i.e., stronger convection) than for the reference runs or the INC runs. For both weather regimes, the model produces a positive relationship of the cloud fraction to the amount of aerosols. However, the height range in which this sensitivity is simulated is much larger (up to 11-12 km AGL) for the days with airmass convection than for the days with frontal systems (2-5 km AGL).

As the averaged cloud fraction shows only small but systematic dependence on the aerosol load, we now investigate the number of clouds together with their sizes. We define a cloud cluster as an area of connected grid points where the liquid water path exceeds $50 \mathrm{~g} \mathrm{~m}^{-2}$. The number of cloud clusters was then counted for every 30-min output file and averaged over time (Fig. 10). For the days with strong large-scale forcing, the number of clouds is rather independent of both the temperature and 

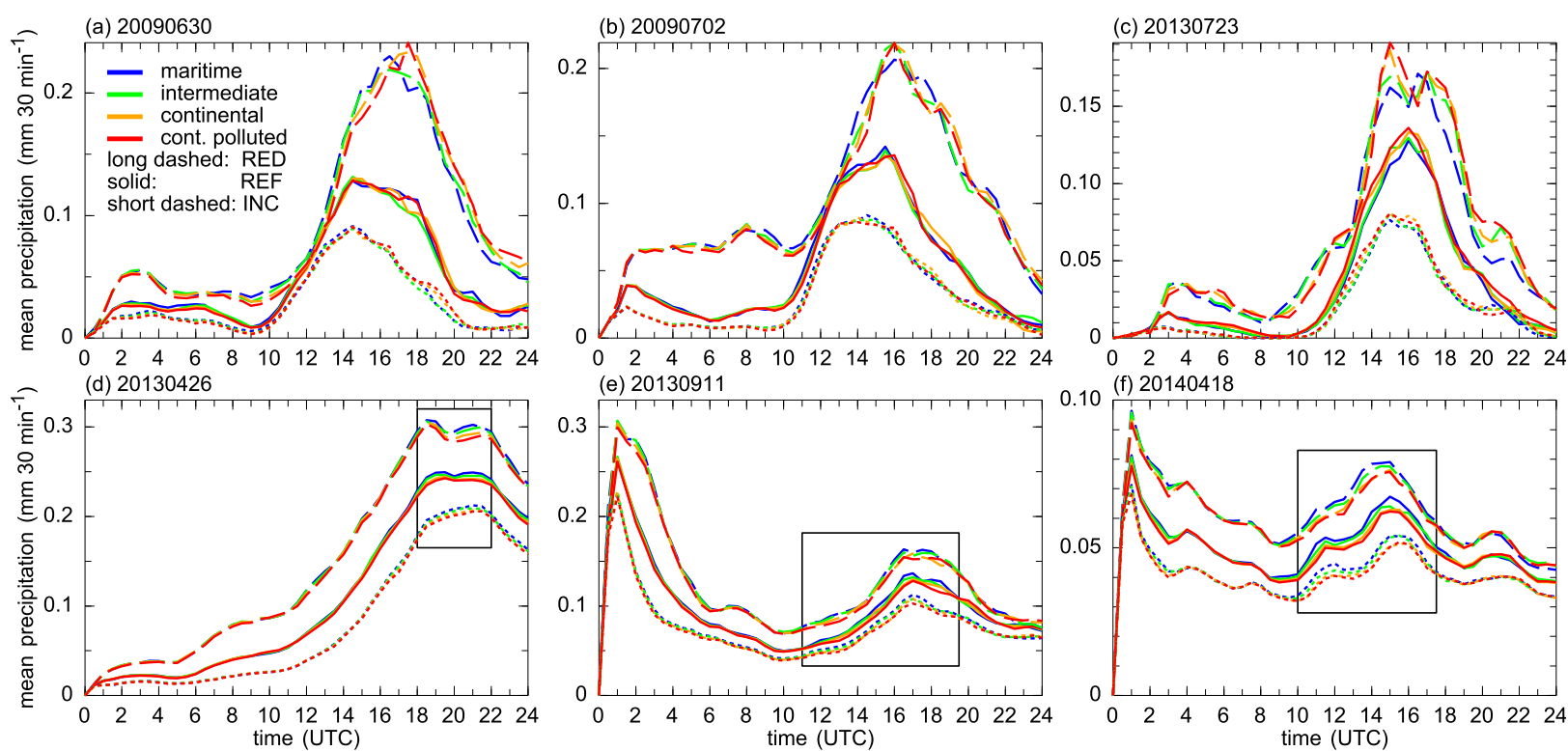

FIG. 7. Domain-averaged precipitation rates for the cases with (a)-(c) weak and (d)-(f) strong large-scale forcing.

the CCN sensitivities. The model simulates small differences only, without any systematic behavior. Only on 26 April 2013 is there a weak decrease of the number of clouds with increasing upper-level temperatures (i.e., decreasing CAPE). On the contrary, the cases with weak synoptic forcing reveal an almost systematic increase in the number of clouds with increasing CCN content. Surprisingly, the different CAPE regimes seem to have little effect on the number of simulated clouds, as the model produces only a few more clouds for increased temperatures. As the mean total cloud cover is almost insensitive to the different aerosol concentrations (less than $1 \%$, not shown), the differences in the number of clouds has to be compensated by different cloud sizes. To test this hypothesis, we computed cloud size distributions following an approach by Neggers et al. (2003). The detected cloud clusters with a liquid water path higher than $50 \mathrm{~g} \mathrm{~m}^{-2}$ are used to determine the cloud size as the diameter of a circle corresponding to this area. Although not being shown here, the averaged cloud size distribution of the 24-h integration period is very similar for the cases with strong synoptic forcing. There is no difference between the individual $\mathrm{CCN}$ sensitivity runs nor between the temperature sensitivities. The simulations for the weakly forced cases reveal that for polluted conditions, the number of small clouds increases weakly, whereas larger clouds occur less often. As assumed earlier, the increase in cloud number is mainly due to a redistribution of the different cloud sizes. As smaller clouds are subject to stronger entrainment and evaporation compared to wider clouds, this could be important for total rain accumulations at the ground.

\section{c. Cloud condensate}

As the sensitivity of the domain-averaged cloud fraction to changes in the aerosol concentration is small, we now investigate the evolution of the cloud condensate, defined as the sum of cloud water, cloud ice, rainwater, snow, graupel, and hail. We describe one case for each weather regime, since the response is similar in each weather regime. For the sake of brevity,

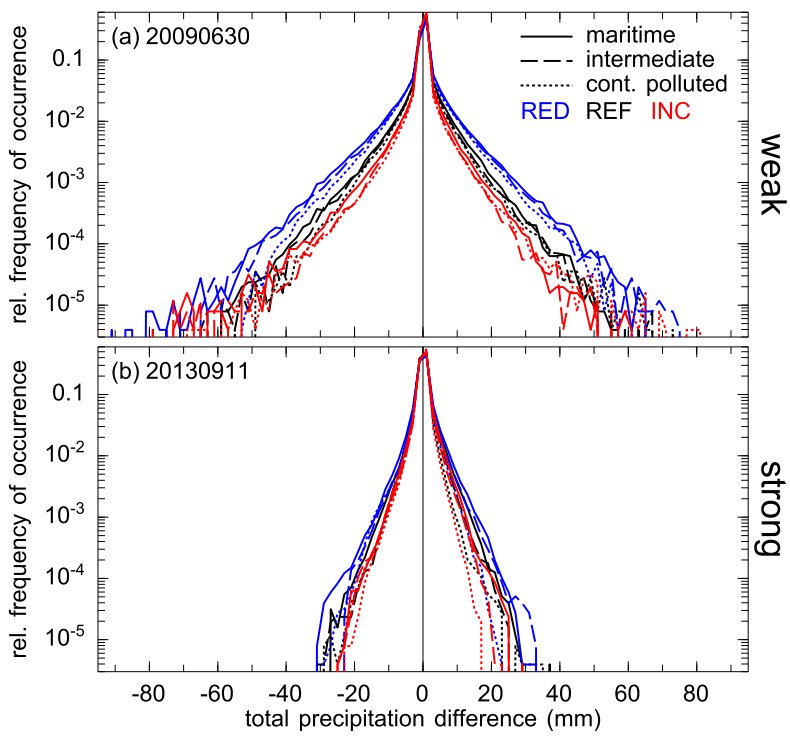

FIG. 8. Probability distributions of 24 -h precipitation difference from the respective runs with continental aerosol for a cases with (a) weak and (b) strong large-scale forcing. RED, REF, and INC indicate runs with reduced, reference, and increased temperature profiles. 

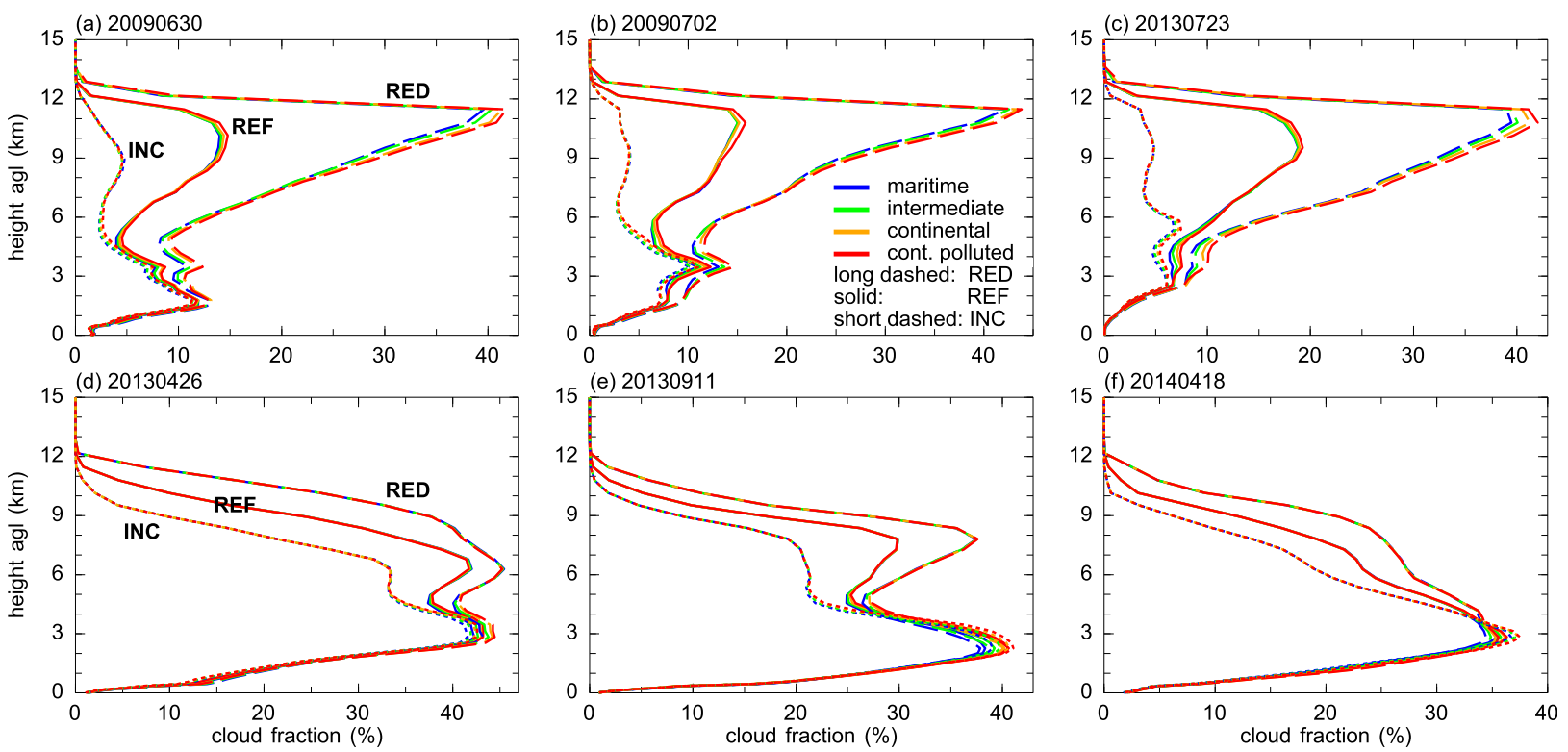

FIG. 9. Vertical profiles of spatiotemporal averages of cloud fraction.

only the respective run with reference temperatures is considered.

\section{1) STRONG SYNOPTIC FORCING: 26 APRIL 2013}

The cloud condensate of the runs with maritime aerosol shows a maximum in the evening (Fig. 11, bottom row). The time corresponds to the highest rain intensities on that day (see Fig. 7). The analysis of the difference fields for the other aerosol assumptions reveals a clear systematic distinction: At lower levels, increasing $\mathrm{CCN}$ leads to a reduction of cloud condensate, whereas at higher levels (up to a height of $6 \mathrm{~km}$ AGL), an increase in cloud condensate is simulated. The boundary between positive and negative responses is

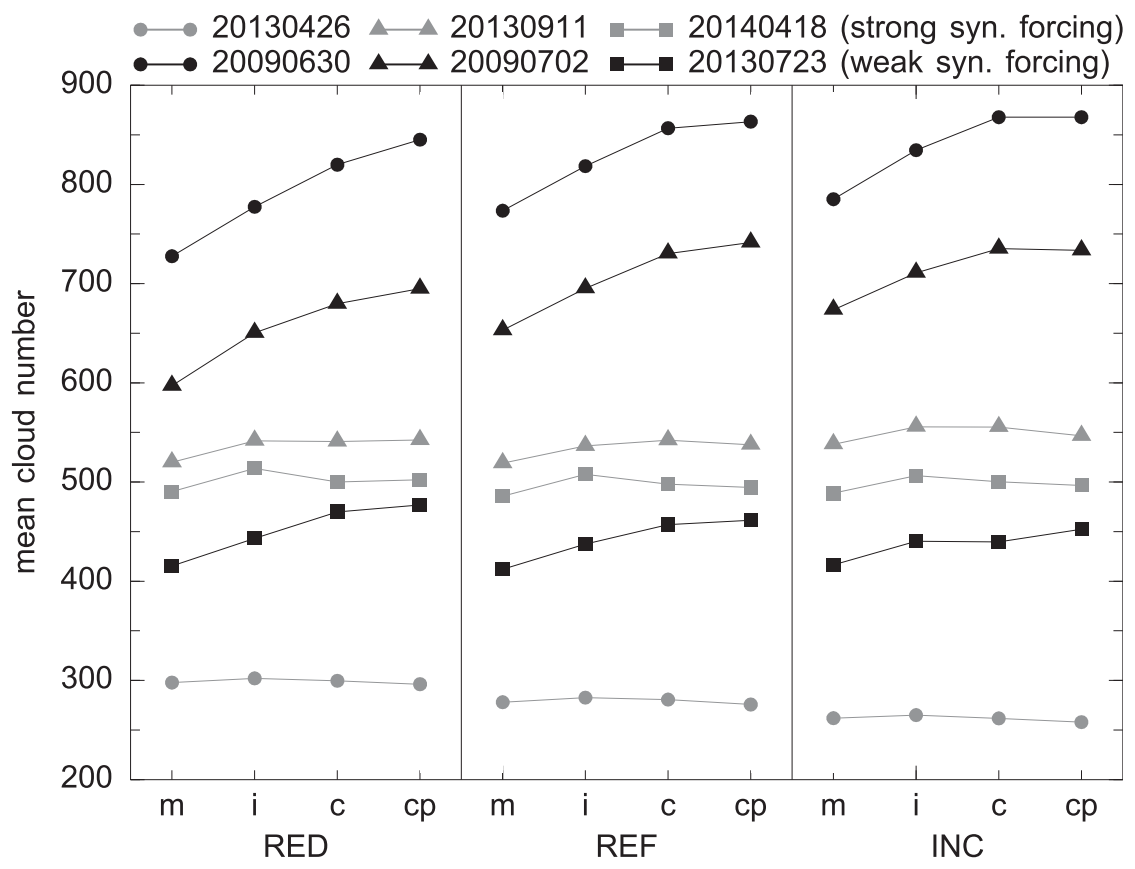

FIG. 10. Spatiotemporal averages of the number of clouds. RED, REF, and INC indicate runs with reduced, reference, and increased temperature profiles. 

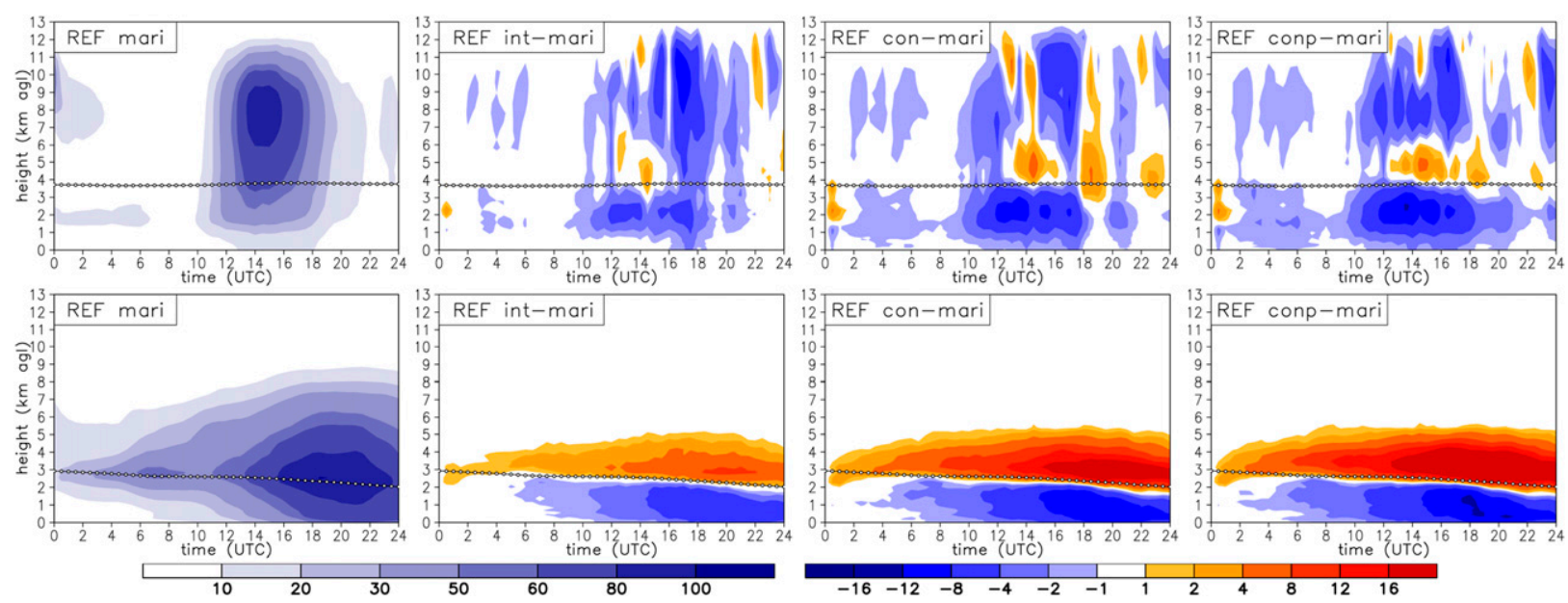

FIG. 11. Domain-averaged vertical profiles of cloud condensate (liquid water, ice, snow, graupel, rain, and hail; $\mathrm{mg} \mathrm{kg}^{-1}$ ) for the (left column) maritime aerosol assumption and (remaining columns) relative differences for the other aerosol assumptions for (bottom) 26 Apr 2013 (strong synoptic forcing) and (top) 30 Jun 2009 (weak synoptic forcing). The lines with open circles indicate the height of the freezing level.

almost perfectly aligned with the domain-averaged freezing level. The freezing level does not lie exactly in the white region that marks the height at which the response to $\mathrm{CCN}$ switches from negative to positive because larger ice particles do not melt instantaneously when reaching the freezing level. Nevertheless, the agreement in the evolution between the region without any response to aerosol content and the height of the freezing level strongly suggests that with increasing CCN concentrations, the warm-rain process is suppressed and the cold-rain process is enhanced [given that the cloud condensate below (above) the freezing level is dominated by raindrops (graupel and snow), see profiles in section 4d]. To further support this conclusion, we calculated spatiotemporally averaged profiles of various microphysical process rates (see Fig. 13d), as some of the rain mass can also be attributed to melted frozen mass that sediments. Our results show that in increasing the $\mathrm{CCN}$ concentration, the contribution of melting to precipitation remains nearly unchanged $(+0.8 \%)$, while accretion (ACC; collection of cloud drops by raindrops) decreases by $12.9 \%$. Moreover, autoconversion is reduced by $69 \%$, which confirms our hypothesis. Furthermore, the enhancement of the cold-rain process is manifested by an increase in vapor deposition of $6.3 \%$. The suppression of the warm-rain process and the reduction of cloud condensate at lower levels corresponds well to the reduction of total precipitation amounts simulated for this type of weather regime (see Fig. 6).

\section{2) WEAK SYNOPTIC FORCING: 30 JUNE 2009}

This weather regime reveals significant differences to the systematic response simulated for strong synoptic forcing. Whereas the vertical extent of the region with aerosol sensitivity was restricted to levels below $6 \mathrm{~km}$ AGL for strong synoptic forcing, the model simulates differences up to the tropopause already shortly after model initialization (Fig. 11, top row). There are two other main differences that are obvious from this figure: (i) the freezing level is no longer the height at which the response to CCN systematically switches from negative to positive and (ii) primarily above the freezing level, both positive and negative responses can occur in one configuration alternating. The larger vertical extent of regions with aerosol sensitivity indicates a larger role of the cold-rain process for this type of weather regime. Although not shown here, we also find a stronger influence of the different temperature regimes: In contrast to the case with strong synoptic forcing, the sensitivity of the cloud condensate to the different aerosol assumptions is larger for reduced temperatures than for the reference run and the run with increased temperatures. We therefore conclude that the stronger the convection is, the larger the involved aerosol-cloud interactions are. This is not true for cases with strong synoptic forcing, where the different temperature regimes do not greatly influence the sensitivity of cloud condensate to aerosol assumptions. The occasionally alternating positive and negative deviations at higher levels also reflects the more chaotic nature of the atmosphere in convective weather events. Moreover, this nonsystematic response links well to the lack of a systematic response of total precipitation found earlier (see Fig. 6).

\section{d. Convective invigoration}

Despite many efforts with field experiments, analysis of satellite measurements, and state-of-the-art numerical 
models, the validity of the invigoration effect and the possibility of climate responses to this effect are still considered to be open questions (Altaratz et al. 2014). To investigate the existence of convective invigoration in our simulations, we computed domain averages of the cloud condensate for the reference runs of all days. The evolution of a threshold of $1 \mathrm{mg} \mathrm{kg}^{-1}$ indicating the approximate location of the cloud top shows almost identical values for the clean and polluted $\mathrm{CCN}$ assumptions on days with strong synoptic forcing (Fig. 12). As expected, the cases with weak synoptic forcing show generally deeper clouds than on days with strong forcing. Even though there are some deviations between the respective clean and polluted cases, we do not find a distinct sign of convective invigoration for these cases. For most of the time, the selected threshold is even located at higher altitudes for the clean conditions than for polluted conditions. These findings confirm the response of the cloud fraction (see Fig. 9), which showed only a minor increase in cloud fraction for polluted conditions but no systematic shift in vertical direction.

To further elucidate this and to explore the microphysical processes involved, we now investigate spatiotemporally averaged profiles of all hydrometeors and microphysical process rates. As the systematic behavior is similar in each weather regime class, we show only one example of each in Fig. 13. The mean cloud water profiles of both days reveal a systematic increase with higher CCN concentration, whereas the rainwater is reduced. As mentioned earlier, this can be attributed to the suppression of the warm-rain process in higher $\mathrm{CCN}$ regimes, which is apparent in the smaller autoconversion rates. Accretion of cloud and rain droplets is also reduced but to a lower degree than autoconversion. However, the maximum accretion rates are found in the respective intermediate runs. Even though the integrated rainwater content is much higher in clean conditions, the profiles also reveal that all curves converge toward the ground, which can be used to explain the missing systematic response of total precipitation to $\mathrm{CCN}$ assumptions despite the systematic decrease of the total rainwater content. The responsible process is the evaporation of rain droplets, which is higher for clean conditions. The raindrop size distributions calculated at various levels reveal shifts to populations of raindrops that are fewer in number but larger in size in more polluted conditions, in agreement with previous studies (e.g., Altaratz et al. 2008; Storer et al. 2010; May et al. 2011). The smaller surface area of large raindrops relative to their volume leads to reduced evaporation when compared to smaller raindrops. We therefore conclude that the higher number of small raindrops under clean conditions is responsible for the stronger evaporation and converging profiles toward the ground.

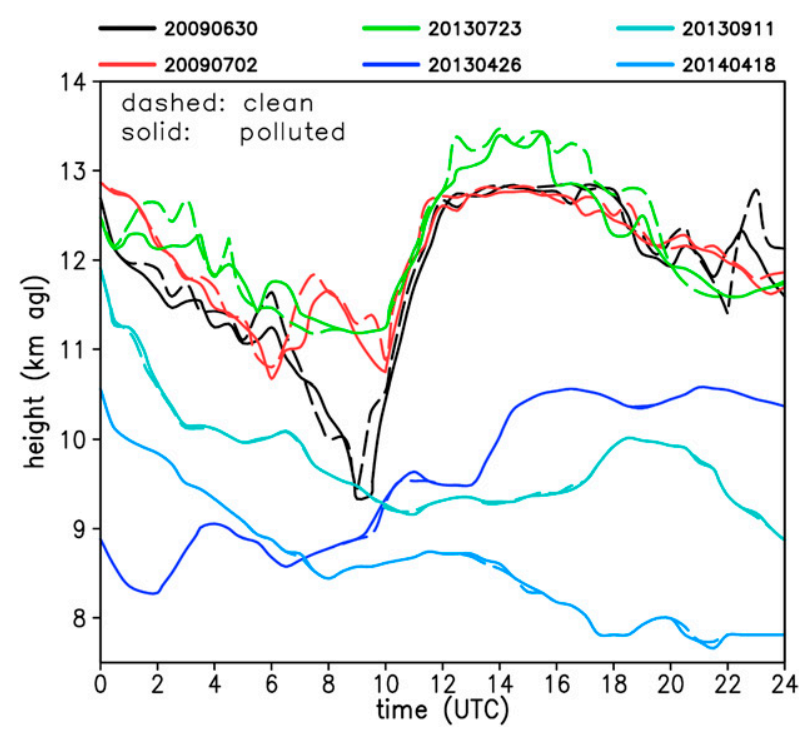

FIG. 12. Upper boundary of domain-averaged cloud condensate of $1 \mathrm{mg} \mathrm{kg}^{-1}$ (condensate includes cloud water, ice, snow, graupel, hail, and rain) for all days with the respective reference temperature profile (clean and polluted conditions only).

Whereas there is no hail and almost no sensitivity of the cloud ice content to the prescribed $\mathrm{CCN}$ concentration for the strongly forced case, the suppression of the warmrain process and the larger water load at higher levels leads to an increase in cloud ice in the weakly forced case. Vapor deposition shows only a minor response to changes in aerosol concentration in that weather regime, but the model simulates an increase in cloud freezing for polluted conditions in heights where cloud ice increases (not shown). The maximum hail, graupel, and snow contents decrease with increasing $\mathrm{CCN}$ for the weakly forced case, while riming (collection of rain and cloud water) is reduced. There is a narrow height range between 5 and $8 \mathrm{~km}$ where riming increases, but the rates are much smaller $\left(0-0.8 \times 10^{-5} \mathrm{~g} \mathrm{~kg}^{-1} \mathrm{~s}^{-1}\right)$ than in the dominant region below $\left(3.5-4.3 \times 10^{-5} \mathrm{~g} \mathrm{~kg}^{-1} \mathrm{~s}^{-1}\right)$. Graupel shows the same response to $\mathrm{CCN}$ under strong synoptic forcing, in agreement with the systematic reduction in riming, but the snow content reveals a minor increase with increasing $\mathrm{CCN}$. The reduction in riming for high aerosol loading was also found by, among others, Cui et al. (2011). They argue that the growth rate of graupel particles by riming is determined by the size of the graupel, the concentration and size distribution of drops, and the collision kernel. When the aerosol concentration is high, the concentration of drops is high but the graupel particles are small and the graupel-drop collision kernel is low, which results in a reduction in riming.

When comparing both weather regimes, we find that mostly the maximum of the hydrometeor profiles is shifted 

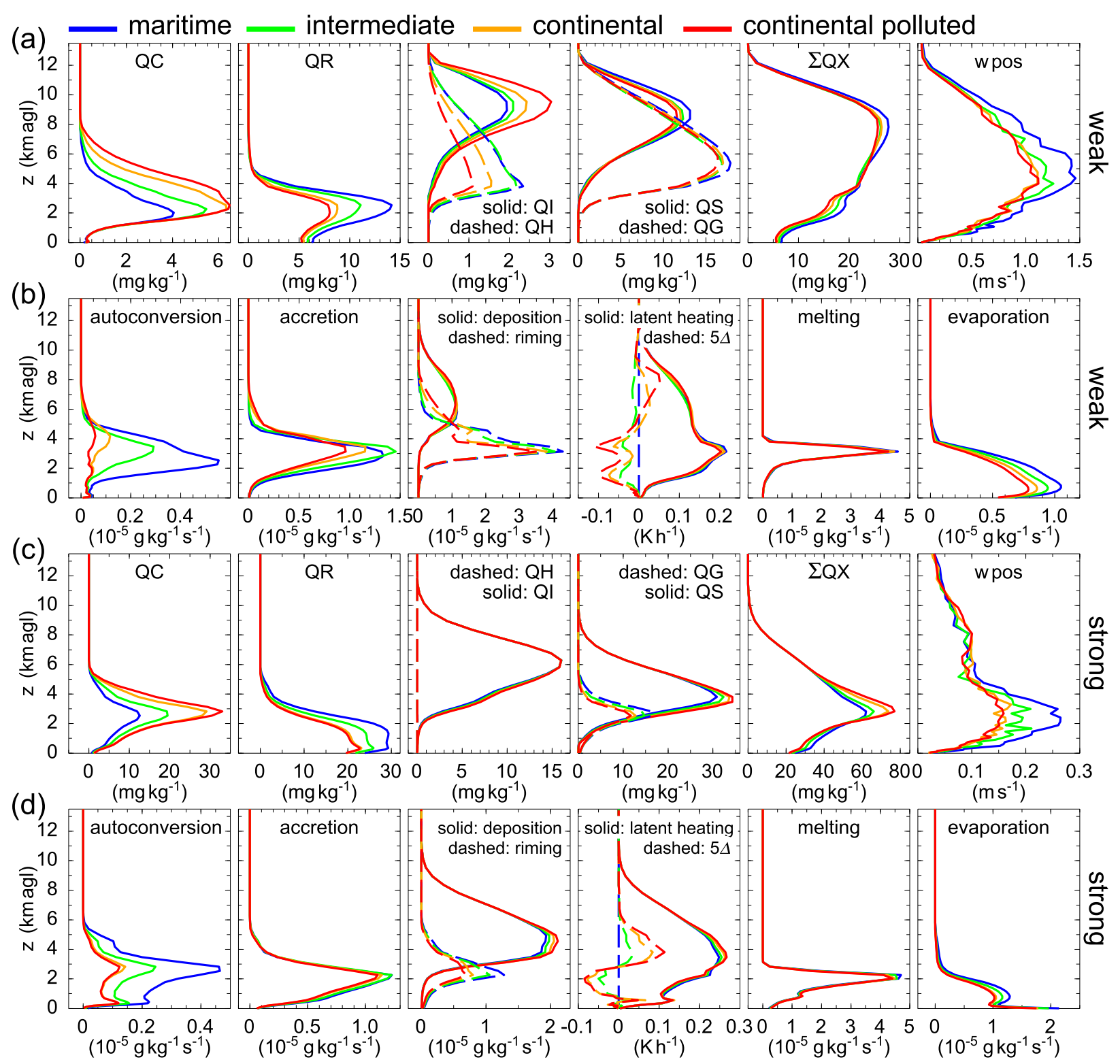

$\left(\mathrm{m} \mathrm{s}^{-1}\right)$

FIG. 13. Vertical profiles of spatiotemporal averages of cloud water (QC), rainwater (QR), cloud ice (QI), hail (QH), snow (QS), graupel (QG), cloud condensate ( $\mathrm{QQX})$, updraft velocities, and microphysical process rates for a case with (a),(b) weak synoptic forcing (30 Jun 2009) and (c),(d) strong synoptic forcing (26 April 2013) of the respective reference run. Latent heating rate profiles are also displayed as differences to the respective maritime conditions and multiplied with a factor of 5 for better visibility. The vertical velocity profiles were calculated with cloudy grid points only.

to larger/smaller values. The vertical extent of the $\mathrm{CCN}$ sensitivity is rather small for strong synoptic forcing. On the other hand, the weakly forced case shows also variations in height of the cloud/rainwater content. The total cloud condensate under strong synoptic forcing shows smaller values for polluted conditions below $2 \mathrm{~km}$ AGL and higher values above (see Fig. 11 for the evolution). The percentage deviations from polluted to maritime conditions is surprisingly high
( $-16 \%$ to $+29 \%$ ), given that the response of the total precipitation is rather weak for that weather regime. In contrast, the profiles for the weak forcing case show almost throughout the entire troposphere more condensate for maritime conditions. However, changes to the $\mathrm{CCN}$ content are simulated from the ground up to roughly a height of $11-12 \mathrm{~km}$ AGL with smaller deviations $(-25 \%$ to $+1.5 \%)$. An important finding is the fact that the vertical velocities (averaged over the 
updraft regions only) become weaker with increased $\mathrm{CCN}$ concentrations. This is contrary to the convective invigoration hypothesis, which assumes updraft invigoration by latent heating. The COSMO model systematically produces lower mean updraft velocities throughout most of the troposphere for weak forcing and the lowest $5 \mathrm{~km} \mathrm{AGL}$ for strong forcing. The latent heating rate profiles reveal only minor variations with different $\mathrm{CCN}$ concentrations. For the strong synoptic forcing case, there is a systematic decrease below $3 \mathrm{~km}$ AGL and an increase aloft with higher CCN concentrations (neglecting the lowest $500 \mathrm{~m}$ ). The increase between 3 and $6 \mathrm{~km}$ AGL coincides with larger vapor deposition rates. The weakly forced case also reveals a reduction below the freezing level but an increase aloft for the continental and continental polluted runs. As these profiles do not exhibit strong differences and the height of the maximum latent heat release remains identical in all runs, there is no convection invigoration. The weaker updrafts in polluted conditions could be one of the reasons why a systematic precipitation response to the aerosol amounts is not present. Both the averaged velocities and the maximum updrafts at $5 \mathrm{~km}$ AGL reveal lower values for polluted conditions throughout the course of our simulations. Specific reasons for these results are unclear, but they may be due to updrafts in polluted conditions containing more water and therefore being less buoyant. We calculated the density of the air parcels using the numerical algorithm of Jaramillo and Mesa (2017) and found higher values for polluted conditions, which supports the fact that cloudy air is usually denser than moist air without droplets at the same pressure and temperature. This illustrates that the aerosol-induced effect is influenced by the balance between latent heating and the increase in condensed water aloft, which were found to have opposing effects on buoyancy (Lebo and Seinfeld 2011). In the study of Seifert and Beheng (2006b), ordinary cells also showed a negative aerosol effect (reduction of vertical wind speed), while for multicells the continental aerosols lead to higher updraft velocities. They argue that for maritime aerosol, less water freezes and it freezes at lower levels, which boosts the dynamics more efficiently. In small continental clouds, many particles freeze above the level of the maximum updraft and a large part of the latent heat release does not foster convective processes, but rather triggers gravity waves at higher levels. This argument also holds true for our simulations, as the increase in cloud ice occurs in a height range around $10 \mathrm{~km}$ AGL, which is higher than the simulated maximum updrafts (4-5 km AGL).

We are also interested in the relative importance of the warm- and cold-rain processes for the different weather regimes. We therefore analyze the ratio of the sum of vapor deposition and riming to the sum of autoconversion and accretion and find a dominant coldrain contribution throughout the course of our simulations (Fig. 14). The warm-rain process dominates for the weakest precipitation rates only. Interestingly, the ratios for weak forcing cases converge to values around 4 with increasing precipitation rates, whereas they converge to values around 2 for strong forcing. This implies that the role of the warm-rain process is more important for weather regimes with strong synoptic forcing.

\section{Summary and conclusions}

The objective of this study was to investigate aerosol effects on clouds and precipitation over central Europe in different weather regimes. To this end, we performed convective-scale numerical simulations with the COSMO model for six cases classified into weak and strong large-scale forcing. We introduced a novel technique to change the environmental atmospheric conditions in realistic simulations. By modifying the initial and boundary temperature profiles with a linear increasing temperature increment, we offer a unique examination of the sensitivity of aerosol-cloud interactions over a range of thermodynamic conditions. All simulations were repeated with four different $\mathrm{CCN}$ concentrations.

As expected, we found that the lower the temperature is, the larger the total precipitation amounts are (due to higher CAPE), irrespective of the type of weather regime. Because of the suppression of the warm-rain process, we find a weak but systematic decrease of total precipitation with increasing $\mathrm{CCN}$ for the cases with strong synoptic forcing. However, there is no systematic aerosol effect for the cases with weak synoptic forcing. This could be partly attributed to the nonlinear character of microphysics and the evaporation of raindrops at lower levels as well as to a shift in cloud sizes to more smaller clouds, which are subject to stronger entrainment and evaporation compared to wider clouds. Besides the important role of wind shear for isolated storms (Fan et al. 2009), the evaporation at lower levels is considered to be a key process in determining whether higher $\mathrm{CCN}$ concentrations reduce or enhance precipitation (e.g., Tao et al. 2007). Furthermore, we find that temperature modifications can also lead to different aerosol-precipitation relations but only in cases with weak synoptic forcing.

In agreement with findings by, for example, Seifert et al. (2012) and Gayatri et al. (2017), the aerosol effects on precipitation averaged over large domains are small. However, over mountainous terrain, we find a stronger 

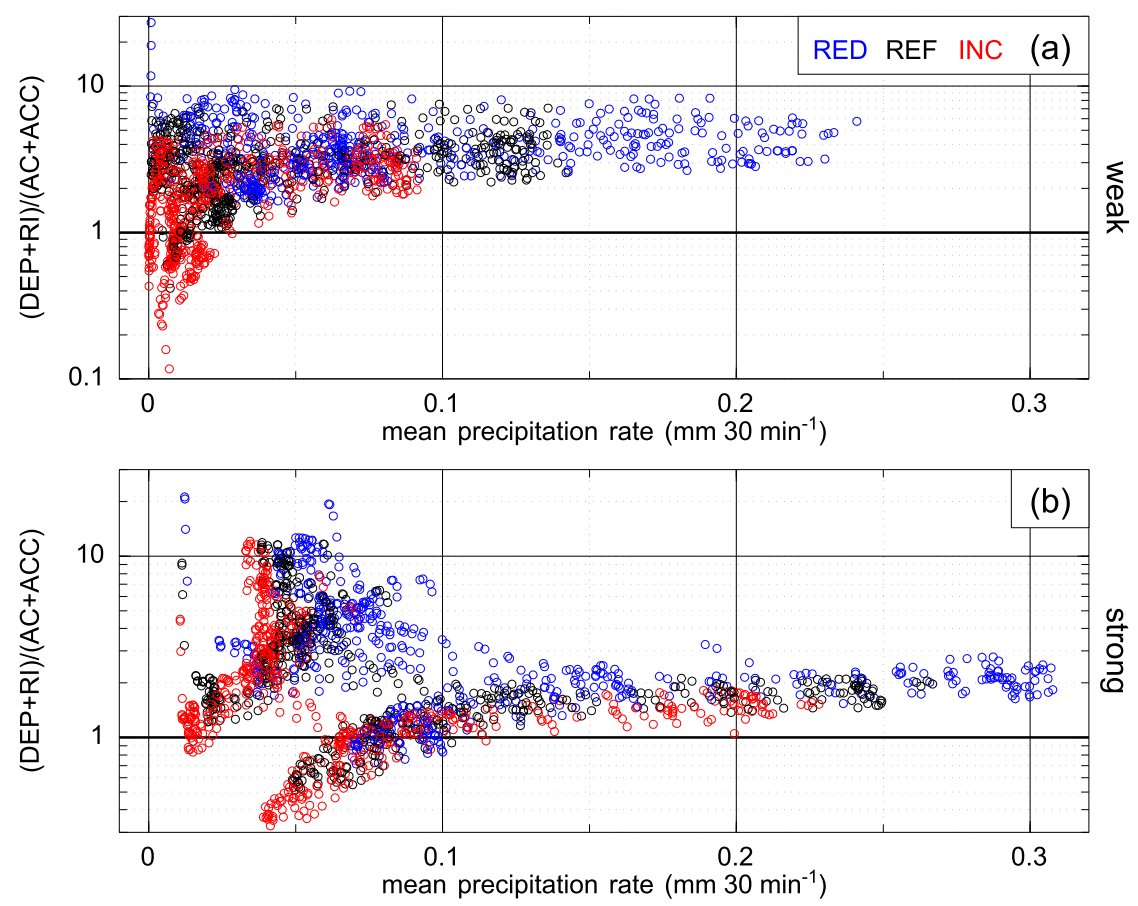

FIG. 14. Ratio of cold-rain formation [deposition (DEP) and riming (RI)] to warm-rain formation (AC and ACC) for all cases with (a) weak and (b) strong synoptic forcing as a function of mean precipitation rate.

sensitivity of precipitation to the aerosol load than averaged over the entire simulation domain. We argue that the fast rain formation in low $\mathrm{CCN}$ conditions is coupled to the dynamical forcing of the orography, whereas in high CCN conditions, the slower rain formation reduces the impact of orographic obstacles. These stronger local responses and precipitation accumulation differences of more than $90 \mathrm{~mm}$ suggests that especially for weak synoptic forcing, correct aerosol assumptions are important and also more relevant for operational weather forecasting. The analysis of different thermodynamical conditions revealed that in all strongly forced cases and in one weakly forced case, the aerosol effect on the surface precipitation systematically increased with increased temperatures (lower CAPE).

Given the weak large-scale response in precipitation and cloud fraction, we find a surprisingly strong aerosol effect on condensate amounts of cloud water, rain, and ice. The total cloud condensate showed a well-defined systematic response for strong synoptic forcing, that is, an increase in condensate above the freezing level and a decrease below the freezing level with increasing CCN. In contrast, the days with weak synoptic forcing revealed a nonsystematic response below and above the freezing level with $\mathrm{CCN}$ effects up to the tropopause. Our simulations did not reveal an invigoration of convective clouds, as the cloud depth did not increase and the updrafts were not enhanced for polluted conditions. In fact, the model simulates an increase in latent heat release above the freezing level for polluted conditions, but the amounts are only marginal. The freezing at lower levels for maritime aerosol seems to boost the dynamics more efficiently for our simulations, in agreement with findings by Seifert and Beheng (2006b). The missing convection invigoration in our model results could also be influenced by the saturation adjustment scheme to treat condensational growth, as this technique has been shown to enhance condensation and latent heating at lower levels, which could limit the potential for an CCN increase to increase buoyancy at mid- to upper levels (Lebo et al. 2012).

Moreover, many more feedbacks, such as weaker or stronger cold pools and the initiation or intensification of secondary cells are involved, all of which could not be investigated here. Our findings also demonstrate that the role of the warm-rain process is higher for strong than for weak synoptic forcing. We further find that the aerosol effects are largest for weakly forced conditions but more predictable for strongly forced conditions because of a consistent precipitation signal. However, the environmental conditions affected by our temperature increments (i.e., instability, CAPE, relative humidity) are much more important than accurate aerosol assumptions, especially for weak large-scale forcing. 
Acknowledgments. This work is a contribution to the Transregional Collaborative Research Center SFB/TRR 165 "Waves to Weather," funded by the German Science Foundation (DFG). The authors wish to thank the Deutscher Wetterdienst (DWD) for providing the COSMO model code and the initial and boundary data, as well as RADOLAN precipitation data and radiosonde observations. This work was performed on the computational resource ForHLR I, funded by the Ministry of Science, Research and the Arts Baden-Württemberg and Deutsche Forschungsgemeinschaft (DFG). We are also grateful to Dr. A. Barrett (KIT) for his help in introducing microphysical process rates in the COSMO model output.

\section{REFERENCES}

Adams-Selin, R. D., S. C. van den Heever, and R. H. Johnson, 2013: Impact of graupel parameterization schemes on idealized bow echo simulations. Mon. Wea. Rev., 141, 1241-1262, https://doi.org/10.1175/MWR-D-12-00064.1.

Albrecht, B. A., 1989: Aerosols, cloud microphysics, and fractional cloudiness. Science, 245, 1227-1230, https://doi.org/10.1126/ science.245.4923.1227.

Altaratz, O., I. Koren, T. Reisin, A. Kostinski, G. Feingold, Z. Levin, and Y. Yin, 2008: Aerosols' influence on the interplay between condensation, evaporation and rain in warm cumulus cloud. Atmos. Chem. Phys., 8, 15-24, https://doi.org/ 10.5194/acp-8-15-2008.

,-- , L. Remer, and E. Hirsch, 2014: Review: Cloud invigoration by aerosols-Coupling between microphysics and dynamics. Atmos. Res., 140-141, 38-60, https://doi.org/10.1016/ j.atmosres.2014.01.009.

Baldauf, M., A. Seifert, J. Förstner, D. Majewski, and M. Raschendorfer, 2011: Operational convective-scale numerical weather prediction with the COSMO model: Description and sensitivities. Mon. Wea. Rev., 139, 3887-3905, https://doi.org/10.1175/MWR-D-10-05013.1.

Barthlott, C., and C. Hoose, 2015: Spatial and temporal variability of clouds and precipitation over Germany: Multiscale simulations across the "gray zone." Atmos. Chem. Phys., 15, 12 361-12 384, https://doi.org/10.5194/acp-15-12361-2015.

_ B. Mühr, and C. Hoose, 2017: Sensitivity of the 2014 Pentecost storms over Germany to different model grids and microphysics schemes. Quart. J. Roy. Meteor. Soc., 143, 1485 1503, https://doi.org/10.1002/qj.3019.

Cohard, J.-M., and J.-P. Pinty, 2000: A comprehensive twomoment warm microphysical bulk scheme. I: Description and tests. Quart. J. Roy. Meteor. Soc., 126, 1815-1842, https:// doi.org/10.1256/smsqj.56613.

Cui, Z., S. Davies, K. S. Carslaw, and A. M. Blyth, 2011: The response of precipitation to aerosol through riming and melting in deep convective clouds. Atmos. Chem. Phys., 11, 3495-3510, https://doi.org/10.5194/acp-11-3495-2011.

Dawson, D. T., II, M. Xue, J. A. Milbrandt, and M. K. Yau, 2010: Comparison of evaporation and cold pool development between single-moment and multimoment bulk microphysics schemes in idealized simulations of tornadic thunderstorms. Mon. Wea. Rev., 138, 1152-1171, https://doi.org/10.1175/2009MWR2956.1.

Dipankar, A., B. Stevens, R. Heinze, C. Moseley, G. Zängl, M. Giorgetta, and S. Brdar, 2015: Large eddy simulation using the general circulation model ICON. J. Adv. Model. Earth Syst., 7, 963-986, https://doi.org/10.1002/2015MS000431.

Fan, J., and Coauthors, 2009: Dominant role by vertical wind shear in regulating aerosol effects on deep convective clouds. J. Geophys. Res., 114, d22206, https://doi.org/10.1029/2009JD012352.

—, L. R. Leung, D. Rosenfeld, Q. Chen, Z. Li, J. Zhang, and H. Yan, 2013: Microphysical effects determine macrophysical response for aerosol impacts on deep convective clouds. Proc. Natl. Acad. Sci. USA, 110, E4581-E4590, https://doi.org/ 10.1073/pnas.1316830110.

, Y. Wand, D. Rosenfeld, and X. Liu, 2016: Review of aerosol-cloud interactions: Mechanisms, significance, and challenges. J. Atmos. Sci., 73, 4221-4252, https://doi.org/10.1175/JAS-D-16-0037.1.

_ L. R. Leung, D. Rosenfeld, and P. J. DeMott, 2017: Effects of cloud condensation nuclei and ice nucleating particles on precipitation processes and supercooled liquid in mixed-phase orographic clouds. Atmos. Chem. Phys., 17, 1017-1035, https:// doi.org/10.5194/acp-17-1017-2017.

Gayatri, K., S. Patade, and T. V. Prabha, 2017: Aerosol-cloud interaction in deep convective clouds over the Indian peninsula using spectral (bin) microphysics. J. Atmos. Sci., 74, 31453166, https://doi.org/10.1175/JAS-D-17-0034.1.

Grabowski, W. W., and H. Morrison, 2017: Modeling condensation in deep convection. J. Atmos. Sci., 74, 2247-2267, https://doi.org/ 10.1175/JAS-D-16-0255.1.

Grant, L. D., and S. C. van den Heever, 2015: Cold pool and precipitation responses to aerosol loading: Modulation by dry layers. J. Atmos. Sci., 72, 1398-1408, https://doi.org/10.1175/ JAS-D-14-0260.1.

Hande, L. B., C. Engler, C. Hoose, and I. Tegen, 2016: Parameterizing cloud condensation nuclei concentrations during HOPE. Atmos. Chem. Phys., 16, 12 059-12 079, https://doi.org/ 10.5194/acp-16-12059-2016.

Heinze, R., and Coauthors, 2017: Large-eddy simulations over Germany using ICON: A comprehensive evaluation. Quart. J. Roy. Meteor. Soc., 143, 69-100, https://doi.org/10.1002/qj.2947.

Heise, E., B. Ritter, and E. Schrodin, 2006: Operational implementation of the multilayer soil model. Deutscher Wetterdienst Tech. Rep. 9, 19 pp., http://www.cosmo-model.org/content/ model/documentation/techReports/docs/techReport09.pdf.

Igel, A. L., M. R. Igel, and S. C. van den Heever, 2015: Make it a double? Sobering results from simulations using singlemoment microphysics scheme. J. Atmos. Sci., 72, 910-925, https://doi.org/10.1175/JAS-D-14-0107.1.

Jaramillo, A., and O. J. Mesa, 2017: On the relative density of clouds. Quart. J. Roy. Meteor. Soc., 143, 2650-2653, https://doi. org/10.1002/qj.3099.

Kalina, E. A., K. Friedrich, H. Morrison, and G. H. Bryan, 2014: Aerosol effects on idealized supercell thunderstorms in different environments. J. Atmos. Sci., 71, 4558-4580, https://doi.org/ 10.1175/JAS-D-14-0037.1.

Keil, C., F. Heinlein, and G. C. Craig, 2014: The convective adjustment time-scale as indicator of predictability of convective precipitation. Quart. J. Roy. Meteor. Soc., 140, 480-490, https:// doi.org/10.1002/qj.2143.

Khain, A. P., and A. Pokrovsky, 2004: Simulation of effects of atmospheric aerosols on deep turbulent convective clouds using a spectral microphysics mixed-phase cumulus cloud model. J. Atmos. Sci., 61, 2983-3001, https://doi.org/10.1175/JAS-3281.1.

_, N. BenMoshe, and A. Pokrovsky, 2008: Factors determining the impact of aerosols on surface precipitation from clouds: An attempt at classification. J. Atmos. Sci., 65, 1721-1748, https://doi.org/10.1175/2007JAS2515.1. 
Kirshbaum, D. J., B. Adler, N. Kalthoff, C. Barthlott, and S. Serafin, 2018: Moist orographic convection: Physical mechanisms and links to surface-exchange processes. Atmosphere, 9, 80, https:// doi.org/10.3390/atmos9030080.

Lebo, Z. J., and J. H. Seinfeld, 2011: Theoretical basis for convective invigoration due to increased aerosol concentration. Atmos. Chem. Phys., 11, 5407-5429, https://doi.org/10.5194/acp-11-5407-2011.

- H. Morrison, and J. H. Seinfeld, 2012: Are simulated aerosolinduced effects on deep convective clouds strongly dependent on saturation adjustment? Atmos. Chem. Phys., 12, 9941-9964, https://doi.org/10.5194/acp-12-9941-2012.

Macke, A., and Coauthors, 2017: The $\operatorname{HD}(\mathrm{CP})^{2}$ Observational Prototype Experiment HOPE-An overview. Atmos. Chem. Phys., 17, 4887-4914, https://doi.org/10.5194/acp-17-4887-2017.

May, P. T., V. N. Bringi, and M. Thurai, 2011: Do we observe aerosol impacts on DSDs in strongly forced tropical thunderstorms? J. Atmos. Sci., 68, 1902-1910, https://doi.org/10.1175/2011JAS3617.1.

Mellor, G. L., and T. Yamada, 1974: A hierarchy of turbulence closure models for planetary boundary layers. J. Atmos. Sci., 31, 1791-1806, https://doi.org/10.1175/1520-0469(1974)031<1791: AHOTCM $>2.0 . \mathrm{CO} ; 2$.

Milbrandt, J. A., and M. K. Yau, 2005: A multimoment bulk microphysics parameterization. Part I: Analysis of the role of the spectral shape parameter. J. Atmos. Sci., 62, 3051-3064, https:// doi.org/10.1175/JAS3534.1.

Mohr, S., M. Kunz, A. Richter, and B. Ruck, 2017: Statistical characteristics of convective wind gusts in Germany. Nat. Hazards Earth Syst. Sci., 17, 957-969, https://doi.org/10.5194/ nhess-17-957-2017.

Molthan, A. L., and B. A. Colle, 2012: Comparisons of single- and double-moment microphysics schemes in the simulation of a synoptic-scale snowfall event. Mon. Wea. Rev., 140, 29823002, https://doi.org/10.1175/MWR-D-11-00292.1.

Morrison, H., G. Thompson, and V. Tatarskii, 2009: Impact of cloud microphysics on the development of trailing stratiform precipitation in a simulated squall line: Comparison of oneand two-moment schemes. Mon. Wea. Rev., 137, 991-1007, https://doi.org/10.1175/2008MWR2556.1.

Neggers, R. A. J., H. J. J. Jonker, and A. P. Siebesma, 2003: Size statistics of cumulus cloud populations in large-eddy simulations. J. Atmos. Sci., 60, 1060-1074, https://doi.org/10.1175/ 1520-0469(2003)60<1060:SSOCCP $>2.0 . C O ; 2$.

Noppel, H., U. Blahak, A. Seifert, and K. D. Beheng, 2010: Simulations of a hailstorm and the impact of $\mathrm{CCN}$ using an advanced two-moment cloud microphysical scheme. Atmos. Res., 96, 286301, https://doi.org/10.1016/j.atmosres.2009.09.008.

Ritter, A., and J.-F. Geleyn, 1992: A comprehensive radiation scheme for numerical weather prediction models with potential applications in climate simulations. Mon. Wea. Rev., 120,303-325, https:// doi.org/10.1175/1520-0493(1992)120<0303:ACRSFN>2.0.CO;2.

Rosenfeld, D., U. Lohmann, G. Raga, C. O'Dowd, M. Kulmala, S. Fuzzi, A. Reissell, and M. Andreae, 2008: Flood or drought: How do aerosols affect precipitation? Science, 321, 1309-1313, https://doi.org/10.1126/science.1160606.

Saleeby, S. M., S. R. Herbener, S. C. van den Heever, and T. L'Ecuyer, 2015: Impacts of cloud droplet-nucleating aerosols on shallow tropical convection. J. Atmos. Sci., 72, 13691385, https://doi.org/10.1175/JAS-D-14-0153.1.

Schättler, U., G. Doms, and C. Schraff, 2016: A description of the nonhydrostatic regional COSMO-model. Part VII: User's guide. Deutscher Wetterdienst, 194 pp., http:// www.cosmo-model.org/content/model/documentation/ core/cosmoUserGuide.pdf.
Schneider, L., C. Barthlott, A. I. Barrett, and C. Hoose, 2018: The precipitation response to variable terrain forcing over low mountain ranges in different weather regimes. Quart. J. Roy. Meteor. Soc., 144, 970-989, https://doi.org/10.1002/qj.3250.

Segal, Y., and A. Khain, 2006: Dependence of droplet concentration on aerosol conditions in different cloud types: Application to droplet concentration parameterization of aerosol conditions. J. Geophys. Res., 111, D15240, https://doi.org/10.1029/2005JD006561.

Seifert, A., and K. D. Beheng, 2006a: A two-moment cloud microphysics parameterization for mixed-phase clouds. Part I: Model description. Meteor. Atmos. Phys., 92, 67-82, https:// doi.org/10.1007/s00703-005-0113-3.

— , and _ 2006b: A two-moment cloud microphysics parameterization for mixed-phase clouds. Part II: Maritime vs. continental deep convective storms. Meteor. Atmos. Phys., 92 , 45-66, https://doi.org/10.1007/s00703-005-0112-4.

_ C. Köhler, and K. Beheng, 2012: Aerosol-cloud-precipitation effects over Germany as simulated by a convective-scale numerical weather prediction model. Atmos. Chem. Phys., 12, 709-725, https://doi.org/10.5194/acp-12-709-2012.

Stevens, B., and G. Feingold, 2009: Untangling aerosol effects on clouds and precipitation in a buffered system. Nature, $\mathbf{4 6 1}$, 607-613, https://doi.org/10.1038/nature08281.

Storer, R. L., and S. C. van den Heever, 2013: Microphysical processes evident in aerosol forcing of tropical deep convective clouds. J. Atmos. Sci., 70, 430-446, https://doi.org/10.1175/ JAS-D-12-076.1.

$\longrightarrow,-$ _ and G. L. Stephens, 2010: Modeling aerosol impacts on convective storms in different environments. J. Atmos. Sci., 67, 3904-3915, https://doi.org/10.1175/2010JAS3363.1.

Tao, W.-K., X. Li, A. Khain, T. Matsui, S. Lang, and J. Simpson, 2007: Role of atmospheric aerosol concentration on deep convective precipitation: Cloud-resolving model simulations. J. Geophys. Res., 112, D24S18, https://doi.org/10.1029/2007JD008728.

_ J.-P. Chen, Z. Li, C. Wang, and C. Zhang, 2012: Impact of aerosols on convective clouds and precipitation. Rev. Geophys., 50, RG2001, https://doi.org/10.1029/2011RG000369.

Theunert, F., and A. Seifert, 2006: Simulation studies of shallow convection with the convection-resolving version of DWD Lokal-Modell. COSMO Newsletter, No. 6, DWD, Offenbach am Main, Germany, 121-128, http://www.cosmo-model.org/ content/model/documentation/newsLetters/newsLetter06/ newsLetter_06.pdf .

Tiedtke, M., 1989: A comprehensive mass flux scheme for cumulus parameterization in large-scale models. Mon. Wea. Rev., 117, 1779-1800, https://doi.org/10.1175/1520-0493(1989)117<1779: ACMFSF $>2.0 . \mathrm{CO} ; 2$.

Twomey, S., 1977: The influence of pollution on the shortwave albedo of clouds. J. Atmos. Sci., 34, 1149-1152, https://doi. org/10.1175/1520-0469(1977)034<1149:TIOPOT>2.0.CO;2.

van den Heever, S. C., G. L. Stephens, and N. B. Wood, 2011: Aerosol indirect effects on tropical convection characteristics under conditions of radiative-convective equilibrium. J. Atmos. Sci., 68 , 699-718, https://doi.org/10.1175/2010JAS3603.1.

White, B., E. Gryspeerdt, P. Stier, H. Morrison, G. Thompson, and Z. Kipling, 2017: Uncertainty from the choice of microphysics scheme in convection-permitting models significantly exceeds aerosol effects. Atmos. Chem. Phys., 17, 12 145-12 175, https:// doi.org/10.5194/acp-17-12145-2017.

Wicker, L. J., and W. C. Skamarock, 2002: Time-splitting methods for elastic models using forward time schemes. Mon. Wea. Rev., 130, 2088-2097, https://doi.org/10.1175/1520-0493(2002) $130<2088$ :TSMFEM $>2.0$. CO 2 . 